Research Article

\title{
Effect of Fiber Angles on Hybrid Double-Tube Concrete Columns under Monotonic Axial Compression
}

\author{
Bing Zhang (D), Yu-Jun Qi, Tao Huang, Qian-Biao Zhang, Yu Hu, and Xia-Min Hu \\ College of Civil Engineering, Nanjing Tech University, Nanjing, China \\ Correspondence should be addressed to Bing Zhang; zhangb@njtech.edu.cn
}

Received 30 September 2019; Accepted 30 November 2019; Published 20 December 2019

Academic Editor: Giovanni Minafò

Copyright (c) 2019 Bing Zhang et al. This is an open access article distributed under the Creative Commons Attribution License, which permits unrestricted use, distribution, and reproduction in any medium, provided the original work is properly cited.

\begin{abstract}
Hybrid double-tube concrete columns (hybrid DTCCs) are a novel form of hybrid columns that combine fiber-reinforced polymer (FRP) composites with two traditional construction materials (i.e., concrete and steel). Hybrid DTCCs consist of an outer FRP tube and an inner steel tube aligned concentrically, with the space between the two tubes and inside of the steel tube filled with concrete. The three materials (i.e., FRP, concrete, and steel) in hybrid DTCCs are combined optimally to deliver excellent performances, such as excellent ductility and remarkable corrosion resistance. Recently, hybrid DTCCs have received increasing research attention on their compressive behavior. Existing studies, however, are focused on hybrid DTCCs with fibers of the FRP tube oriented in the hoop direction or close to the hoop direction. Against this background, this paper presents a series of monotonic axial compression tests on hybrid DTCCs with a particular focus on the effect of fiber angles (i.e., the angle of the fiber orientations to the longitudinal axis of the FRP tube). Three types of fiber angles (i.e., $\pm 45^{\circ}, \pm 60^{\circ}$, or $\pm 80^{\circ}$ ) and two FRP tube thicknesses (i.e., $4 \mathrm{~mm}$ and $8 \mathrm{~mm}$ ) were employed in the present study. Experimental results show that the concrete in hybrid DTCCs is well confined by both the FRP tube and the steel tube, leading to excellent ductility; the confinement effect of the FRP tube increases with the increase of the absolute value of fiber angles, whereas the ultimate axial strain decreases with the increase of the absolute value of fiber angles. An existing analysis-oriented model, which considers the different confining states of the concrete between the two tubes and that inside of the steel tube, is verified using the present test results. The model is capable of providing accurate predictions for hybrid DTCCs with a $\pm 80^{\circ}$ FRP tube. For hybrid DTCCs with a $\pm 45^{\circ}$ or $\pm 60^{\circ}$ FRP tube, the model yields reasonable accurate predictions for the peak axial load but underestimates the ultimate axial strain consistently.
\end{abstract}

\section{Introduction}

Research and applications of structural members with new materials is a major driving force for the development of civil engineering [1]. Fiber-reinforced polymer (FRP) composites have found increasing applications in many areas (e.g., aviation industries, automobile industries, and chemical industries) due to their exceptional advantages (e.g., low density, high strength, and excellent corrosion resistance). As a new material for civil engineering, extensive research has been conducted on applications of FRP composites in the retrofitting of existing structures (e.g., wrapping concrete columns to enhance their seismic ductility, external bonding to concrete beams to improve their flexural strength, and shear strength) $[2,3]$. Over the past two decades, increasing research has been focused on the combined use of FRP with traditional construction materials (i.e., concrete, steel, and timber) to create novel hybrid structural members [4-10].

Concrete-filled FRP tubes (CFFTs) are a novel structural member, in which the FRP tube is used as a confining device for the concrete (Figure 1(a)). When CFFTs are under axial compression, the concrete is under lateral confinement while the FRP tube is under hoop tension. Both the ductility and the strength of the concrete can be greatly improved for CFFTs due to the confinement provided by the FRP tube. Over the past two decades, extensive research has been conducted on CFFTs under various loading conditions and many stress-strain models have been proposed [11-17]. Hybrid FRP-concrete-steel double-skin tubular columns (hybrid DSTCs) (Figure 1(b)) are proposed to combine two traditional construction materials (i.e., concrete and steel) with FRP composites $[18,19]$. Hybrid DSTCs consist of an 


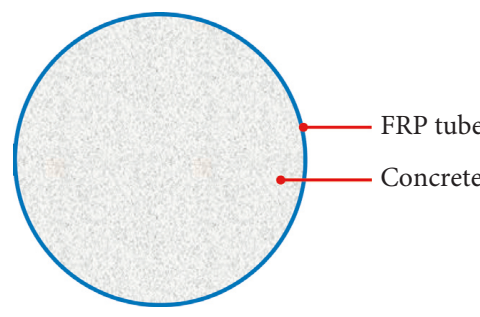

(a)

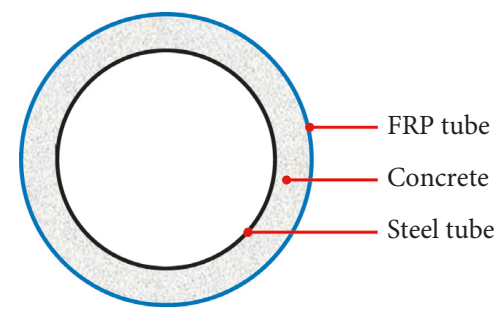

(b)

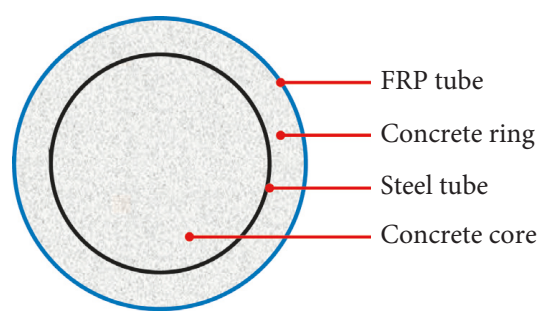

(c)

FIgURE 1: Cross sections of columns with an FRP tube. (a) CFFTs. (b) Hybrid DSTCs. (c) Hybrid DTCCs.

inner tube made of steel, an outer tube made of FRP, and a concrete layer between the two tubes (Figure 1(b)). Since the invention of hybrid DSTCs, extensive studies have been undertaken to study their behaviors under axial compression [20-24], cyclic loading [25, 26], bending [27], and impacting loading [28]. Due to the confinement provided by the two tubes, the concrete in hybrid DSTCs is very well confined, leading to excellent strength enhancement and ductility improvement.

When hybrid DSTCs were first proposed [18, 19], the filling of the inner steel tube with concrete was mentioned as a possible option to enhance their performance further and to suppress the inward buckling of the steel tube. As a variation of hybrid DSTCs, hybrid double-tube concrete columns (hybrid DTCCs) are proposed [29, 30], which consist of an outer FRP tube and an inner steel tube aligned concentrically, with the space between the two tubes and inside of the inner steel tube filled with concrete (Figure 1(c)). In hybrid DTCCs, the inner steel tube provides the primary longitudinal reinforcement, whereas the outer FRP tube protects the inner steel tube from the harsh external environment. The concrete between the tubes (i.e., the concrete ring in Figure 1(c)) is mainly under the confinement of the outer FRP tube, while the concrete inside of the inner steel tube (i.e., the concrete core in Figure 1(c)) is confined by both the FRP tube and the steel tube, leading to even more strength and ductility enhancement compared with hybrid. The FRP tube and the steel tube can be used as the formwork for concrete casting during the construction, thus simplifying the construction process and saving the cost. Ozbakkaloglu's research group [21, 22] conducted a series of axial compression tests on hybrid DSTCs, and hybrid DTCCs were fabricated and tested for comparisons. In their tests, it was confirmed that hybrid DTCCs had much larger averaged stress for the confined concrete yet smaller ultimate axial strain than companion hybrid DSTCs. Teng et al. $[29,30]$ conducted a series of experimental tests on hybrid DTCCs with a high-strength steel tube and confirmed that the buckling of the high-strength steel tube is suppressed so that its high material strength of the steel tube can be effectively utilized to achieve excellent column performance. Zeng et al. [31] explored the possibility of constructing hybrid DTCCs with an outer square FRP tube and an inner circular high-strength steel tube. These tests further confirmed the excellent ductility of hybrid DTCCs even these columns had an outer square FRP tube. Zhang et al.
[26] demonstrated the benefits of the partial concrete filling inside of the steel tube by an experiment of a large-scale column subjected to combined cyclic lateral loading and axial compression. The test results reported by Zhang et al. [26] showed that the energy dissipation capacity was significantly improved and the local buckling of the steel tube was prevented by partially filling the steel tube with concrete. Wang [32] proposed a model for hybrid DTCCs which considers the different confining states of the concrete ring and the concrete core of hybrid DTCCs.

Existing studies, however, are focused on hybrid DTCCs with fibers of the FRP tube oriented in the hoop direction or close to the hoop direction. FRP tubes with fibers oriented in the hoop direction or close to the hoop direction have a greater chance to develop hoop resin cracks due to their low longitudinal stiffness and low longitudinal strength. The hoop resin cracks in the FRP tube have a negative impact on the corrosion resistance of hybrid DTCCs. FRP tubes with nonhoop fibers have fibers interlocked by the overlapped laminates, leading to larger longitudinal stiffness and higher longitudinal strength. Therefore, the possibility to development resin cracks could be reduced for FRP tubes with nonhoop fibers, leading to better corrosion resistance. Against this background, this paper presents a series of monotonic axial compression tests on hybrid DTCCs with a particular focus on the effect of fiber angles (i.e., the angle of the fiber orientations to the longitudinal axis of the FRP tube). Three types of fiber angles (i.e., fiber angles $\theta= \pm 45^{\circ}, \pm 60^{\circ}$, or $\pm 80^{\circ}$ ) and two FRP tube thicknesses (i.e., $4 \mathrm{~mm}$ and $8 \mathrm{~mm}$ ) were employed in the present study. Besides, two types of steel tubes for hybrid DTCCs were also investigated in the present study. The present study will pave way for the design of fiber angles to optimize the performance of hybrid DTCCs.

\section{Experimental Program}

2.1. Specimen Details. A total of 16 hybrid DTCCs were fabricated and tested in the present study (Table 1), which all had a height of $400 \mathrm{~mm}$ and a diameter of $200 \mathrm{~mm}$ (the outer diameter of the concrete ring). Filament-wound glass FRP tubes with three different fiber angles (i.e., fiber angles $\theta= \pm 80^{\circ}, \pm 60^{\circ}$, or $\pm 45^{\circ}$ ) were adopted for these hybrid DTCCs. All filament-wound FRP tubes were manufactured in a professional factory (Guangdong Sunny FRP Corporation, Guangzhou, China) using the same batch of raw materials (i.e., glass fiber and resin). For ease of reference, FRP tubes with 
TABle 1: Details of specimens.

\begin{tabular}{|c|c|c|c|c|c|}
\hline \multirow[b]{2}{*}{ Specimen } & \multicolumn{2}{|c|}{ FRP tube } & \multicolumn{3}{|c|}{ Steel tube } \\
\hline & $\begin{array}{c}t_{\text {frp }} \\
(\mathrm{mm})\end{array}$ & Fiber angles $\theta$ & Type & $d_{\mathrm{s}}(\mathrm{mm})$ & $t_{\mathrm{s}}(\mathrm{mm})$ \\
\hline $\begin{array}{l}\text { A4-F45- } \\
\text { M1,2 }\end{array}$ & 4.0 & $\pm 45^{\circ}$ & A & 140 & 5.0 \\
\hline $\begin{array}{l}\text { A4-F60- } \\
\text { M1,2 }\end{array}$ & 4.0 & $\pm 60^{\circ}$ & A & 140 & 5.0 \\
\hline $\begin{array}{l}\text { A4-F80- } \\
\text { M1,2 }\end{array}$ & 4.0 & $\pm 80^{\circ}$ & A & 140 & 5.0 \\
\hline $\begin{array}{l}\text { B4-F45- } \\
\text { M1,2 }\end{array}$ & 4.0 & $\pm 45^{\circ}$ & B & 120 & 4.5 \\
\hline $\begin{array}{l}\text { B4-F60- } \\
\text { M1,2 }\end{array}$ & 4.0 & $\pm 60^{\circ}$ & B & 120 & 4.5 \\
\hline $\begin{array}{l}\text { B4-F80- } \\
\text { M1,2 }\end{array}$ & 4.0 & $\pm 80^{\circ}$ & B & 120 & 4.5 \\
\hline $\begin{array}{l}\text { A8-F45- } \\
\text { M1,2 }\end{array}$ & 8.0 & $\pm 45^{\circ}$ & A & 140 & 5.0 \\
\hline $\begin{array}{l}\text { A8-F60- } \\
\text { M1,2 }\end{array}$ & 8.0 & $\pm 60^{\circ}$ & A & 140 & 5.0 \\
\hline
\end{tabular}

$\pm 80^{\circ}, \pm 60^{\circ}$, or $\pm 45^{\circ}$ fiber angles are referred to as $\pm 80^{\circ}, \pm 60^{\circ}$, or $\pm 45^{\circ}$ FRP tubes, respectively. There were two thicknesses for $\pm 60^{\circ}$ and $\pm 45^{\circ}$ FRP tubes (i.e., $4 \mathrm{~mm}$ and $6 \mathrm{~mm}$ ), whereas only one thickness for $\pm 80^{\circ}$ FRP tubes (i.e., $4 \mathrm{~mm}$ ). Two types of steel tubes were employed for these hybrid DTCCs, which are referred to as Type A and Type B steel tubes, respectively. The Type A steel tube had an outer diameter of $140 \mathrm{~mm}$ and a thickness of $5.0 \mathrm{~mm}$, whereas the Type B steel tube was $120 \mathrm{~mm}$ in diameter and $4.5 \mathrm{~mm}$ in thickness.

Each specimen was given a name for ease of reference, which consists of three parts as follows: (1) the first part has a letter " $A$ " or " $B$ " to represent the type of the inner steel tube and then followed by " 4 " or " 8 " to indicate the nominal thickness of the FRP tube; (2) the second part has a letter " $F$ " and two digits to represent the fiber angles of the FRP tube; and (3) the final part "M1" or "M2" is used to differentiate two nominally identical specimens of a pair.

2.2. Preparation of Specimens. In the present study, all steel tubes of each type were cut from the same batch steel tubes. All FRP tubes were fabricated using the filament-winding technique, which involves the continuous winding of long glass fibers on a circular mold with the fiber angles and the fiber-to-resin ratio being well controlled. Precise machining was carried out on both the steel tube and the FRP tube to achieve two flat ends which were perpendicular to the longitudinal axis. As shown in Figure 2(a), the two tubes were fixed concentrically on a base plate for concrete casting. It should be noted that strain gauges were installed on the outer surface of the steel tube and their lead wires passed out the FRP tube through two small holes (Figure 2(a)). The FRP tube was wrapped with thin plastic films to keep the outer surface of the FRP tube clean during the concrete casting.

In order to ensure the casting quality of the concrete, self-compacting concrete was employed for these hybrid DTCCs. River sand, tap water, granite aggregated (maximum nominal size: $10 \mathrm{~mm}$ ), ordinary Portland cement, and superplasticizer were used for mixing the concrete. A vibrating rod was used to consolidate the concrete for good casting quality. After the concrete curing and the removal of the base plate, an additional 3-ply glass FRP strip (the total nominal thickness is $1.0 \mathrm{~mm}$ ) was wrapped near the upper and lower ends of hybrid DTCCs to avoid the unexpected premature failure there. Both of the top and bottom ends of the specimen were capped with high-strength gypsum to achieve flat ends which were perpendicular to the longitudinal axis (Figure 2(b)).

\subsection{Material Properties}

2.3.1. FRP Tube. For FRP tubes with the same fiber angles, their hoop tensile properties and axial compressive properties are expected to be identical as they have the same fiber angles, the same glass fibers, and the same resin. Therefore, FRP tubes with a nominal thickness of $4.0 \mathrm{~mm}$ were used to obtain their hoop tensile properties and axial compressive properties.

Split-disk tests are a simple and effective method to determine hoop tensile properties of filament-wound FRP tubes [33-35]. As shown in Figure 3, the test fixture has two half disks which were attached to the upper and lower loading grips via two hinges. The FRP ring is installed on the outer circumference of the two half disks. The FRP ring usually ruptures near the disk gap because of a bending moment imposed during the test near the gap. Therefore, an apparent tensile strength rather than a true tensile strength can be obtained by the split-disk method [33-35]. In order to obtain the hoop tensile properties of FRP tubes, tensile splitdisk tests following ASTM D2290-08 [33] (Figure 3) were carried out on 75 FRP rings. For each type of fiber angles, there were 25 FRP rings which could be further divided into five groups according to their widths (i.e., $20 \mathrm{~mm}, 30 \mathrm{~mm}$, $40 \mathrm{~mm}, 50 \mathrm{~mm}$, and $60 \mathrm{~mm}$ ). FRP rings with different widths were used to investigate the influences of FRP ring width on the test results. As shown in Figure 3, six hoop strain gauges with a gauge length of $20 \mathrm{~mm}$ were attached on each FRP ring, among which two were centered at the two disk gaps, whereas the nearer edges of the other four gauges were located at $15 \mathrm{~mm}$ away from the disk gaps. Four longitudinal strain gauges with a gauge length of $20 \mathrm{~mm}$ were also attached on each FRP tube as shown in Figure 3.

Typical failed FRP rings are shown in Figure 4. Ruptures of fibers were the major failure for $\pm 80^{\circ}$ FRP rings, while the delamination between fiber layers was evident for $\pm 45^{\circ} \mathrm{FRP}$ rings. As for $\pm 60^{\circ} \mathrm{FRP}$ rings, a combination of fiber ruptures and fiber delamination was observed. Figure 5 shows the hoop stress-strain curves for all FRP rings, where the tensile strain was averaged from the four hoop strain gauges away from the disk gaps, while the tensile stress was obtained by dividing the applied tensile force by the cross-sectional area under tension. The two strain gauges at the disk gaps were excluded for the hoop strain as their readings were found to be lower due to the local bending of the FRP ring there. It is evident that $\pm 80^{\circ}$ FRP rings have a linear hoop stress-strain relationship until the final rupture, while $\pm 45^{\circ}$ FRP rings exhibit hoop stress-strain curves with an initial linear 


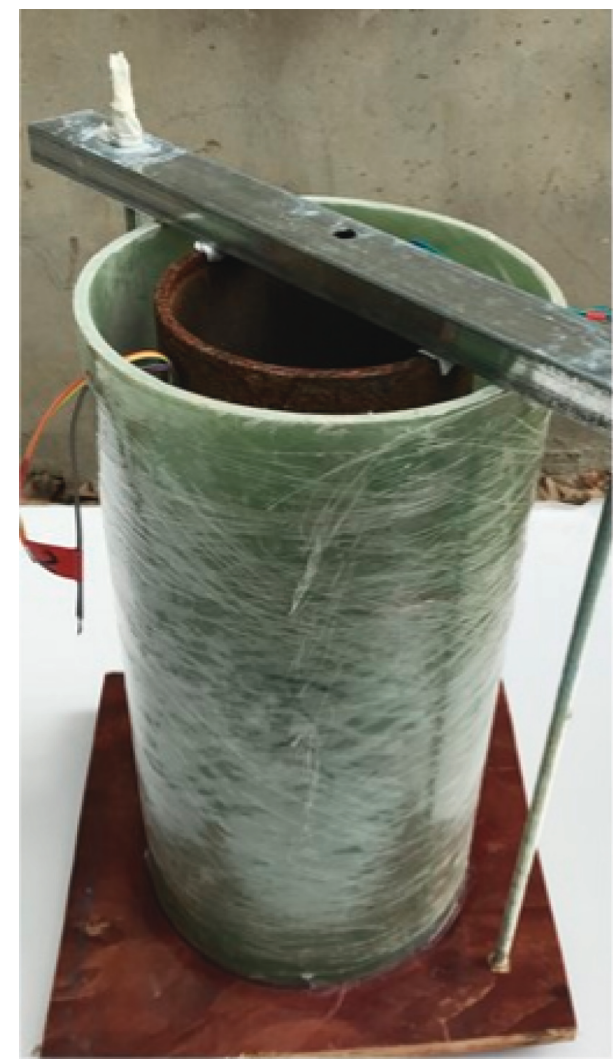

(a)

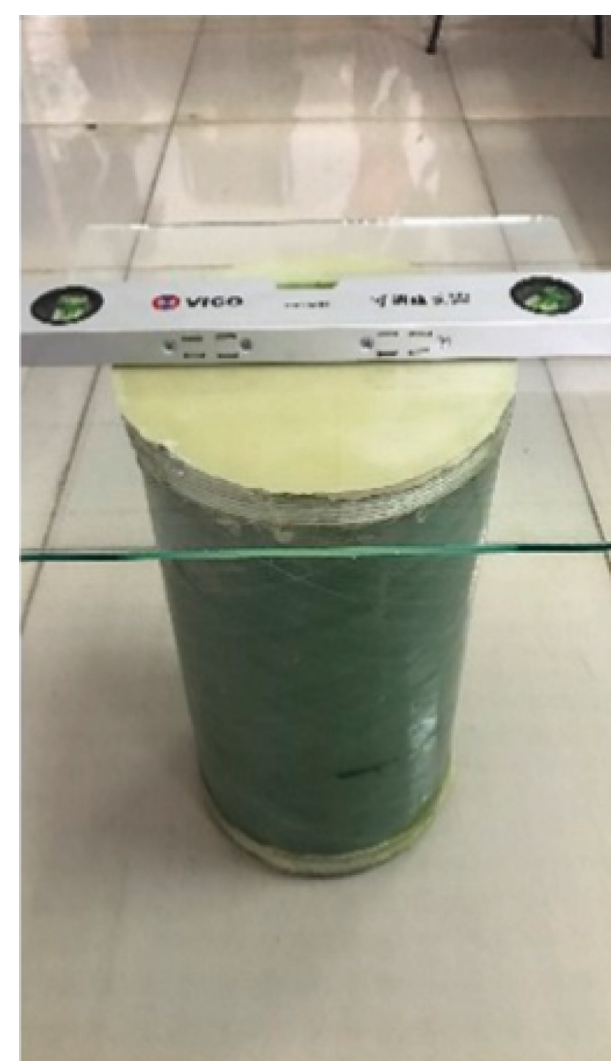

(b)

Figure 2: Preparation of hybrid DTCCs. (a) Formwork. (b) Gypsum capping.
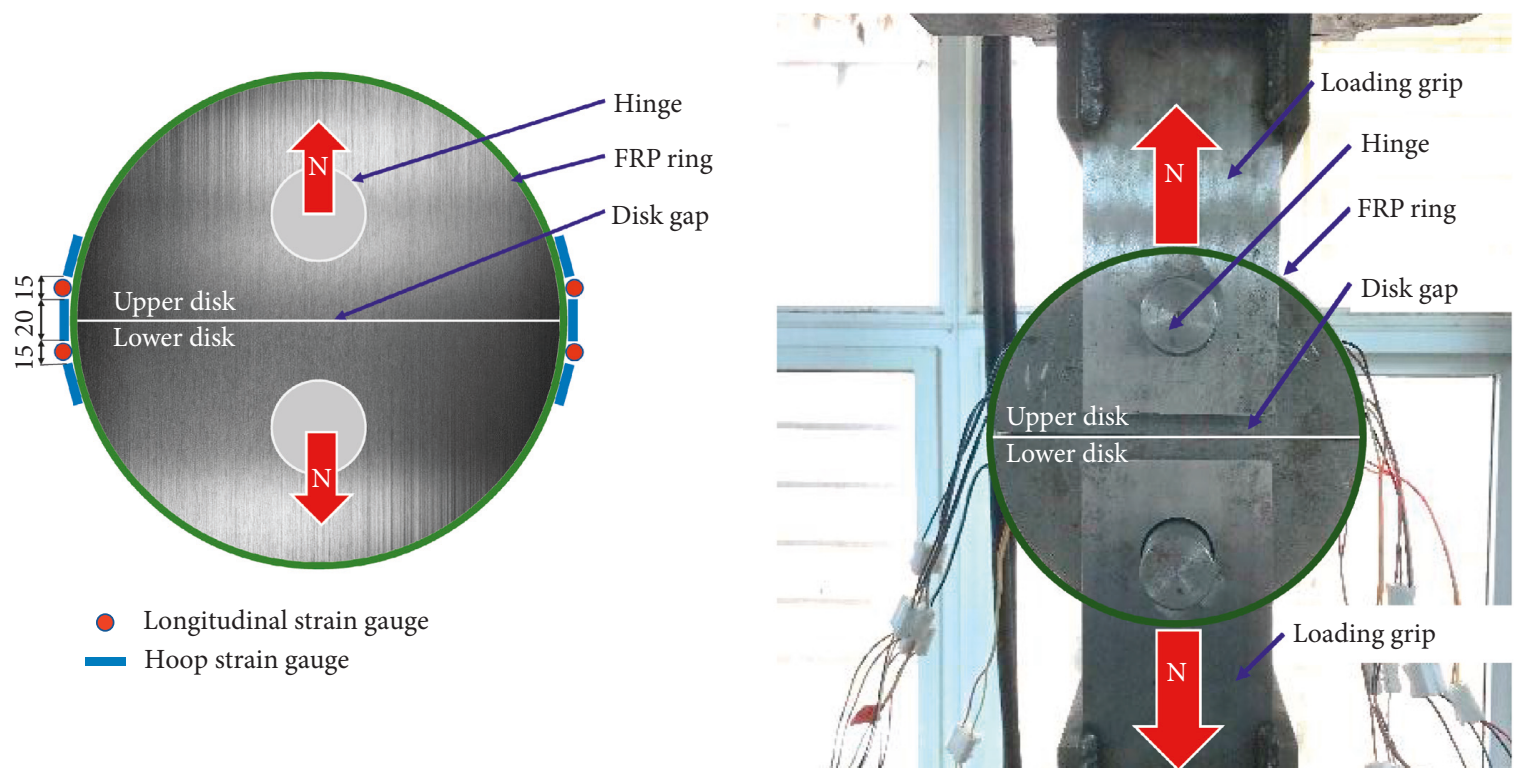

FIgURE 3: Experimental setup for the split-disk test.

portion, a smooth curvy transition, and then a linear portion until the final rupture. In contrast with $\pm 80^{\circ}$ and $\pm 45^{\circ}$ FRP rings, $\pm 60^{\circ} \mathrm{FRP}$ rings display hoop stress-strain curves with small nonlinearity but considerable scatters. The effect of FRP ring width on the peak hoop stress and the ultimate rupture strain is shown in Figure 6. It is evident that, with the increase of the FRP ring width, the peak hoop stress and the ultimate rupture strain of FRP rings increases. As shown in Figure 6 , the effect of FRP ring width on $\pm 45^{\circ}$ FRP rings is noticeable, especially for the ultimate rupture strain. For 


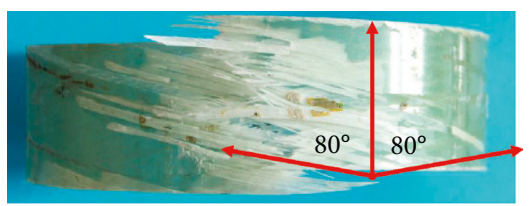

(a)

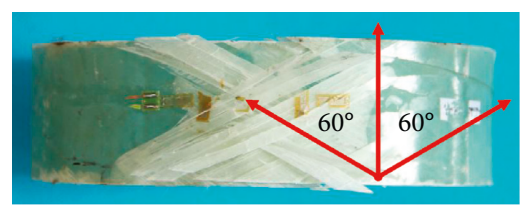

(b)

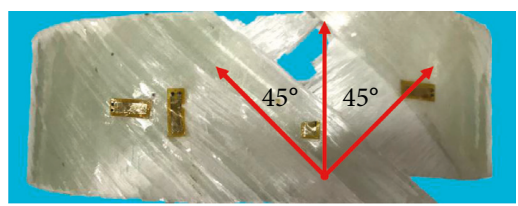

(c)

Figure 4: Typical FRP rings after the split-disk test. (a) $\theta= \pm 80^{\circ} ; 60 \mathrm{~mm}$ in width. (b) $\theta= \pm 60^{\circ} ; 60 \mathrm{~mm}$ in width. (c) $\theta= \pm 45^{\circ} ; 60 \mathrm{~mm}$ in width.

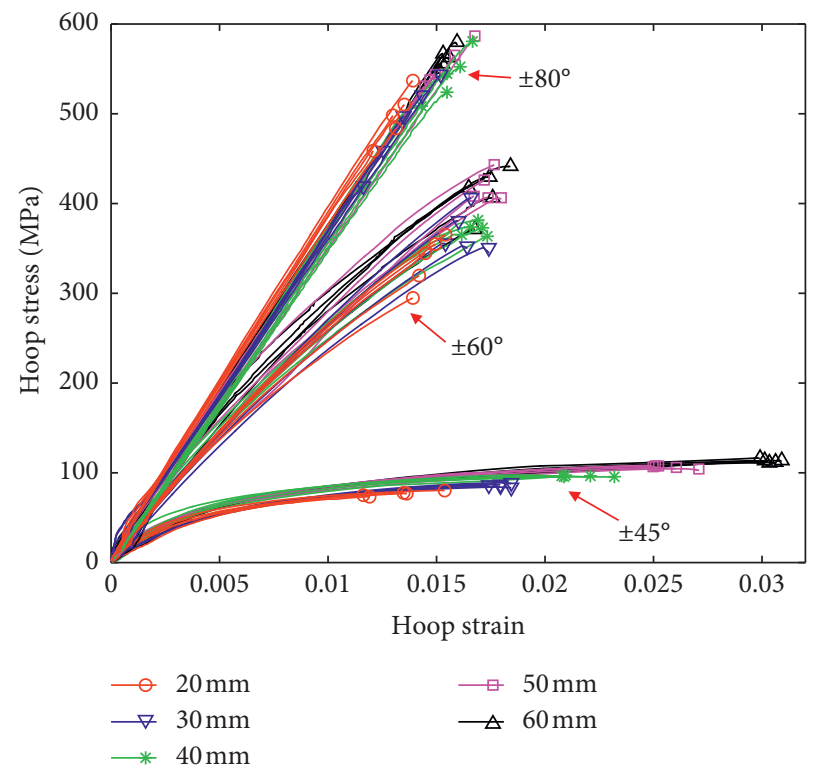

FIGURE 5: Hoop stress-hoop strain curves of FRP rings.

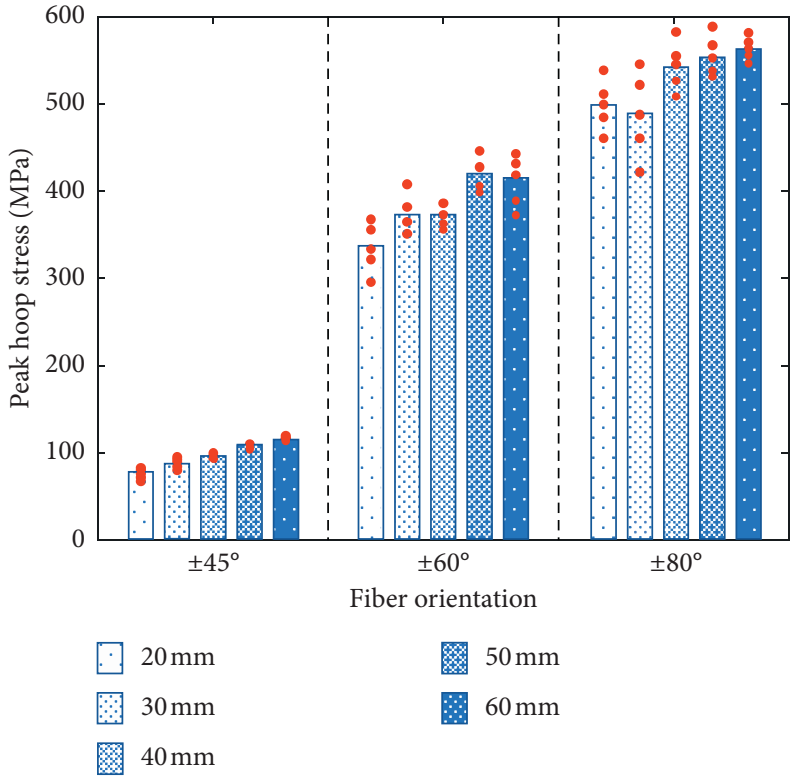

(a)

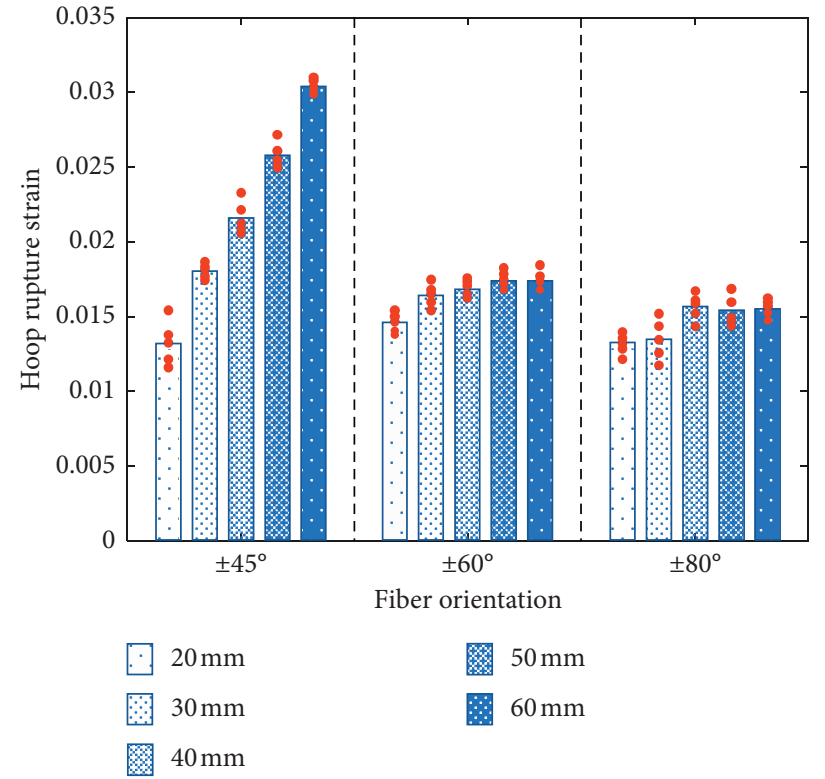

(b)

FIGURE 6: Effect of FRP ring width. (a) Peak hoop stress. (b) Ultimate hoop strain. 
$\pm 60^{\circ}$ and $\pm 80^{\circ}$ FRP rings, the test results obtained from FRP rings with a width of $50 \mathrm{~mm}$ are very close to those with a width of $60 \mathrm{~mm}$. Therefore, it is suggested that the minimum ring width for the split-disk test should be $50 \mathrm{~mm}$. By averaging the test results of FRP rings with the width of $60 \mathrm{~mm}$ (5 rings for each type of fiber angles), test results of FRP rings under hoop tension were obtained as shown in Table 2. $f_{\mathrm{ft}}$, $\varepsilon_{\mathrm{ft}}$, and $E_{\mathrm{ft}}$ are the peak hoop stress, the ultimate hoop strain, and the secant modulus at the peak stress point of FRP rings, respectively. It is evident that the ultimate hoop strain increases with the decrease of the absolute value of fiber angles, while the secant modulus increases with the increase of the absolute value of fiber angles.

In order to obtain the axial compressive properties of FRP tubes, 15 short FRP tubes $(60 \mathrm{~mm}$ in height and $4 \mathrm{~mm}$ in thickness) were tested under axial compression following GB/T5350-2005 [36]. These short FRP tubes of each type were cut from the same batch FRP tubes for hybrid DTCCs. Precise machining was carried out on these short FRP tubes to ensure the flat ends to be perpendicular to the longitudinal axis of the FRP tube. Eight strain gauges were installed on the midheight of the FRP tube. Of the eight strain gauges, four were hoop strain gauges, and the other four were axial strain gauges, which were distributed evenly on the circumference. A displacement control rate of $0.036 \mathrm{~mm} / \mathrm{min}$ (strain rate: $10 \mu \varepsilon / \mathrm{sec}$ ) was adopted for the axial compression test. The test was stopped when the axial load dropped to around $70 \%$ of the peak load. Typical FRP short tubes after the test are shown in Figure 7. It is evident that severe damages were localized near the two ends for $\pm 80^{\circ}$ FRP tubes, whereas $\pm 45^{\circ}$ and $\pm 60^{\circ}$ FRP tubes developed severe damages near the midheight. Resin cracks generally following the orientations of the fibers were observed for all these failed FRP tubes (Figure 7). The axial stress-axial strain curves are shown in Figure 8 for all FRP tubes. $\pm 45^{\circ}$ FRP tubes show a linear axial stress-strain curve until the peak stress, whereas $\pm 80^{\circ}$ and $\pm 60^{\circ}$ FRP tubes exhibit axial stress-strain curves with an initial linear portion and a curvy portion until the peak stress. The axial stiffness and the peak axial stress increased with the decrease of the absolute value of fiber angles. The test results of axial compressive properties of FRP tubes are summarized in Table 3, including the average peak stress $\left(f_{\mathrm{fc}}\right)$, the average strain corresponding to the peak stress $\left(\varepsilon_{\mathrm{fc}}\right)$, and the average secant modulus at the peak stress point $\left(E_{\mathrm{fc}}\right)$.

2.3.2. Concrete. In order to obtain concrete properties, three concrete cylinders with a height of $300 \mathrm{~mm}$ and a diameter of $150 \mathrm{~mm}$ were prepared during the concrete casting for hybrid DTCCs. Concrete properties were then obtained during the testing period of hybrid DTCCs following ASTM C39/39M [37]. The elastic modulus $\left(E_{\mathrm{c}}\right)$, the compressive strength $\left(f_{\mathrm{co}}^{\prime}\right)$, and the compressive strain at the peak stress $\left(\varepsilon_{c o}\right)$ of the unconfined concrete are 23.3 GPa, 29.3 MPa, and $0.24 \%$, respectively.

2.3.3. Steel Tube. Tensile tests on five steel coupons were conducted following BS 18 [38] for Type A and Type B steel
TABle 2: Properties of FRP rings under hoop tension.

\begin{tabular}{lccc}
\hline Fiber angles & $f_{\mathrm{ft}}(\mathrm{MPa})$ & $\varepsilon_{\mathrm{ft}}(\%)$ & $E_{\mathrm{ft}}(\mathrm{GPa})$ \\
\hline $\pm 45^{\circ}$ & 113.5 & 3.03 & 3.9 \\
$\pm 60^{\circ}$ & 413.4 & 1.73 & 24.0 \\
$\pm 80^{\circ}$ & 562.2 & 1.55 & 36.2 \\
\hline
\end{tabular}

tubes, respectively. The average elastic modulus $E_{s}$, the average yield stress $f_{\mathrm{y}}$, and the average ultimate tensile strength $f_{\mathrm{u}}$ are shown in Table 4 . It should be noted that both types of steel tubes have similar tensile properties. In addition, two hollow steel tubes of each type, which had the same height as those used in hybrid DTCCs (i.e., $400 \mathrm{~mm}$ ), were tested under monotonic axial compression. For each steel tube, four hoop strain gauges and four axial strain gauges with a gauge length of $20 \mathrm{~mm}$ were installed at the midheight and evenly distributed circumferentially. Four LVDTs were installed to measure the overall axial shortening. The failed steel tubes after axial compression tests and the axial stress-axial strain curves are all shown in Figure 9, with the axial strain being obtained from LVDTs. As shown in Figure 9(a), all steel tubes showed an elephant-foot buckling failure, which is typical for circular steel tubes. As mentioned above, Type A and Type B steel tubes had similar tensile properties, and their axial stress-axial strain curves also agreed with each other very well (Figure 9(b)).

2.4. Experimental Setup and Instrumentation. As shown in Figure 10, four axial strain gauges and four hoop strain gauges with a gauge length of $20 \mathrm{~mm}$ were installed at the midheight on the outer surface of the FRP tube and evenly distributed along the circumferential direction. In addition, four axial strain gauges and four hoop strain gauges with a gauge length of $10 \mathrm{~mm}$ were attached at the midheight of the outer surface of the steel tube (Figure 10). LVDTs were also employed which covered the full height of hybrid DTCCs (Figure 10). A large testing facility (maximum capacity of $10,000 \mathrm{kN}$ ) was used to conduct these axial compression tests with a displacement control rate of $0.24 \mathrm{~mm} / \mathrm{min}$ (strain rate: $10 \mu \varepsilon / \mathrm{sec}$ ). The axial load was applied to the FRP tube, the steel tube, and the concrete simultaneously. All test data, including the strains, loads, and displacements, were recorded by a data logger.

\section{Test Results and Discussion}

3.1. General. The damage processes of three typical hybrid DTCCs (i.e., specimens B4-F80-M1, B4-F60-M2, and B4F45-M2) are illustrated in Figure 11, while their axial loadaxial shortening curves are shown in Figure 12. The averaged shortening from the four LVDTs were used in Figure 12. In order to investigate the damage process, five representative timepoints (i.e., Timepoints A, B, C, D, and E) are selected to show damage conditions of the FRP tube (Figure 11). In addition, the axial load and the axial shortening at the representative timepoints are marked in Figure 12.

As shown in Figure 11, there was no visible phenomenon on the FRP tube at the beginning (Timepoint A), as these 


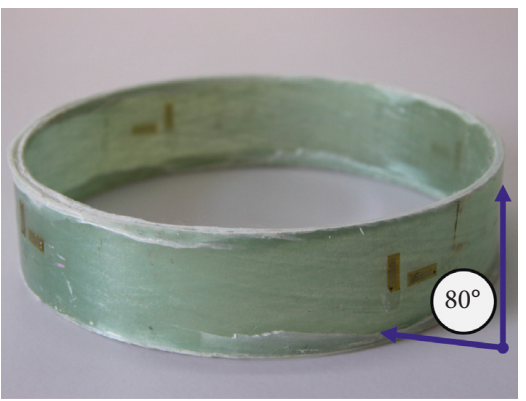

(a)

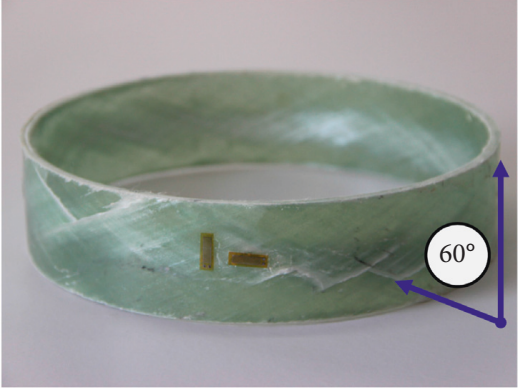

(b)

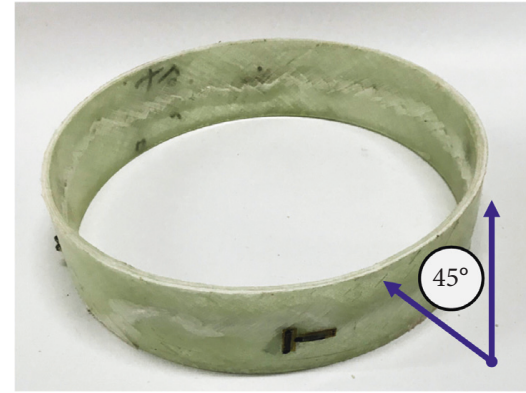

(c)

FIgURE 7: FRP short tubes after axial compression. (a) $\pm 80^{\circ}$. (b) $\pm 60^{\circ}$. (c) $\pm 45^{\circ}$.

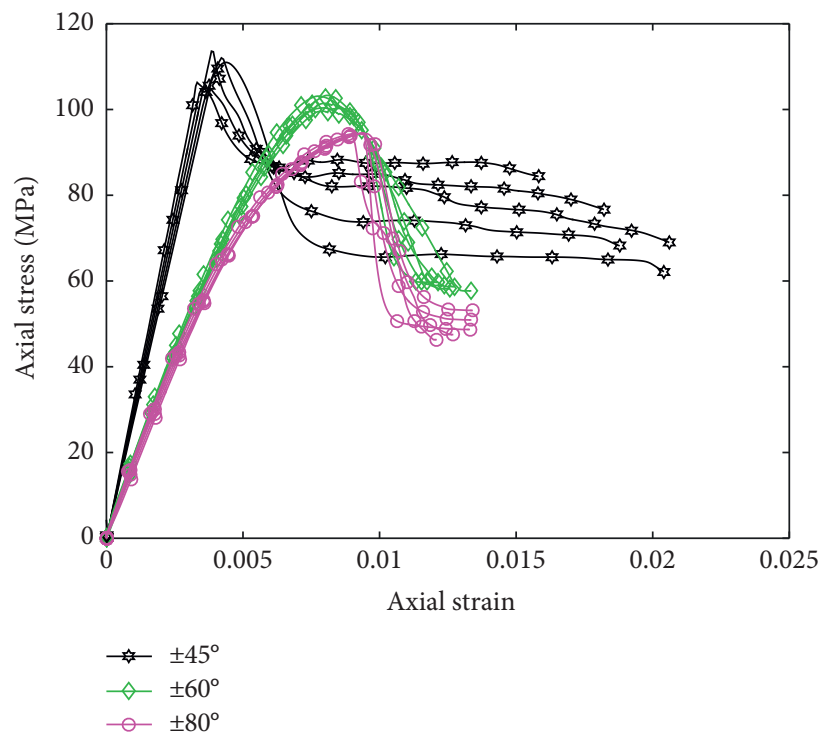

FIgURE 8: Axial stress-axial strain curves of FRP short tubes.

TABLe 3: Properties of short FRP tubes under axial compression.

\begin{tabular}{lccc}
\hline Fiber angles & $f_{\mathrm{fc}}(\mathrm{MPa})$ & $\varepsilon_{\mathrm{fc}}(\%)$ & $\mathrm{E}_{\mathrm{fc}}(\mathrm{GPa})$ \\
\hline $\pm 45^{\circ}$ & 112.3 & 0.387 & 29.0 \\
$\pm 60^{\circ}$ & 102.6 & 0.830 & 12.4 \\
$\pm 80^{\circ}$ & 94.4 & 0.974 & 9.7 \\
\hline
\end{tabular}

hybrid DTCCs were still in the elastic range on their axial load-axial shortening curves (Figure 12). As the loading process progressed, the readings of hoop strain gauges increased significantly at Timepoint B (the axial shortening is around $0.8 \mathrm{~mm}$ ). At Timepoint $\mathrm{B}$ in Figures 11 and 12 , specimens B4-F80-M1 and B4-F60-M2 exhibited no visible phenomenon; however, specimen B4-F45-M2 showed significant local outward buckling near the bottom end. Actually, for all hybrid DTCCs with a $\pm 45^{\circ}$ FRP tube, local outward buckling occurred at the early stage of the test. With the increase of axial deformation, obvious damage in the resin was observed for specimens B4-F60-M2 (Timepoint C) and B4-F80-M1 (Timepoint D in Figures 11(a) and 11(b)). These damages developed subsequently following the fiber orientations. At the final stage, progressive noises associated
TABle 4: Properties of steel coupons.

\begin{tabular}{lccc}
\hline Type & $E_{\mathrm{s}}(\mathrm{GPa})$ & $f_{\mathrm{y}}(\mathrm{MPa})$ & $f_{\mathrm{u}}(\mathrm{MPa})$ \\
\hline A & 205.9 & 365.8 & 438.0 \\
B & 206.1 & 358.7 & 443.0 \\
\hline
\end{tabular}

with the snapping of fibers were noticed. For specimen B4F45-M2, the $\pm 45^{\circ}$ FRP tube developed more severe local buckling and damage when the axial shortening exceeded $40 \mathrm{~mm}$ (Timepoint D in Figures 11(c) and 12). Finally, explosive rupture failure of the FRP tube occurred for all hybrid DTCCs with a big bang noise (Timepoint $\mathrm{E}$ in Figure 11).

Damages to the FRP tube and the inner steel tube were examined as shown in Figure 13. For hybrid DTCCs with a $\pm 80^{\circ}$ FRP tube (Figures 13(a) and 13(b)), major cracks following the orientations of fibers were found on the FRP tube, and the ruptures were localized near the top end. No evident buckling was observed on the steel tube for hybrid DTCCs with a $\pm 80^{\circ}$ FRP tube. As shown in Figures 13(c)13 (e), hybrid DTCCs with a $\pm 60^{\circ}$ FRP tube suffered much more severe damage on the FRP tube with visible zigzag 


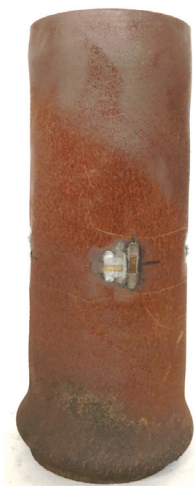

A-1

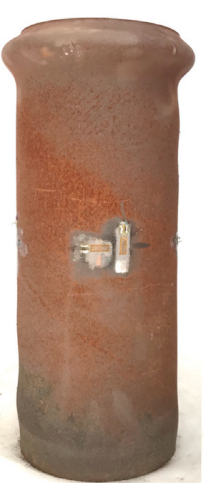

A-2

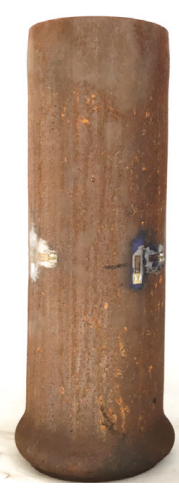

B-1

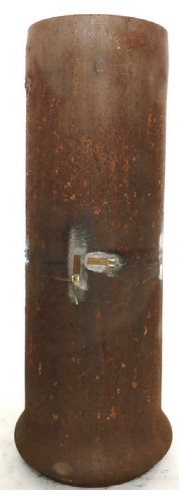

B-2

(a)

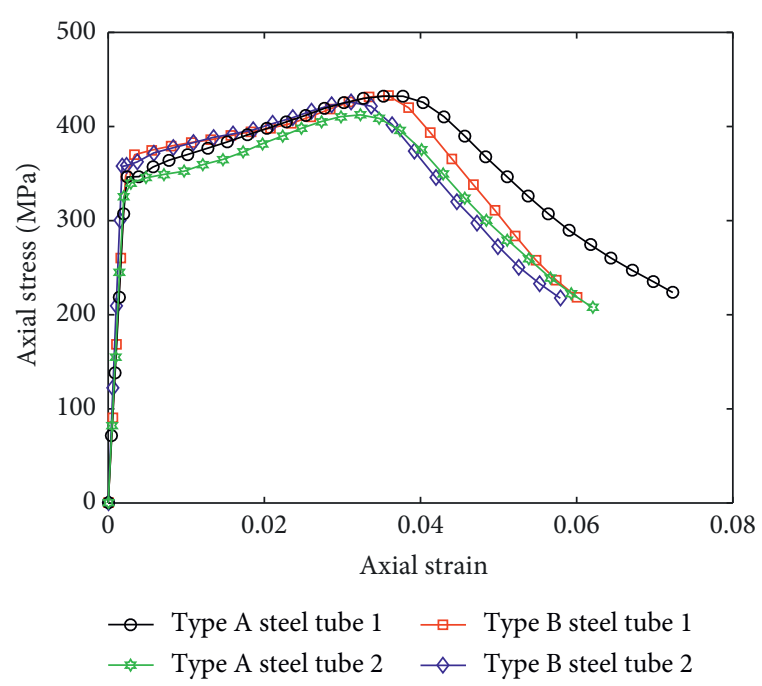

(b)

Figure 9: Hollow steel tubes under axial compression. (a) Local buckling of hollow steel tubes. (b) Axial stress-strain curves.

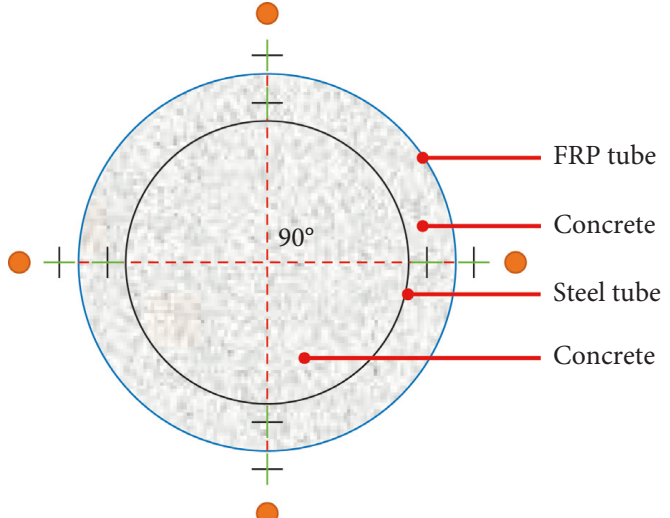

LVDTs

Strain gauges in the hoop direction

Strain gauges in the longitudinal direction

(a)

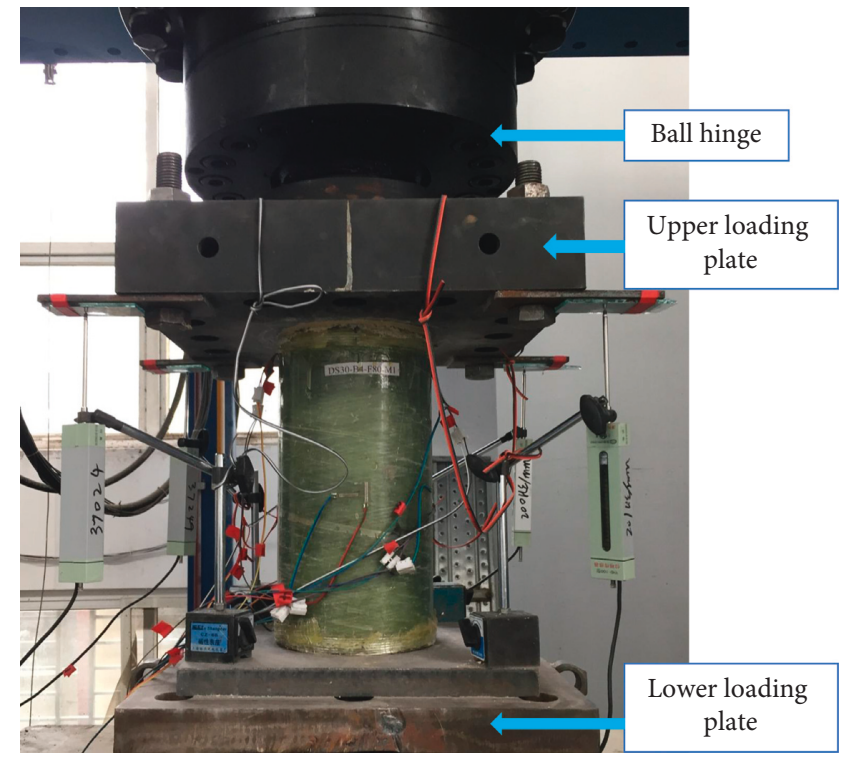

(b)

Figure 10: Experimental setup and instrumentation. (a) Planar layout of strain gauges and LVDTs. (b) Experimental setup.

cracks along the longitudinal direction of the FRP tube, where the delamination of fiber layers and the rupture of fibers occurred. It was apparent that the inner steel tube of hybrid DTCCs with a $\pm 60^{\circ} \mathrm{FRP}$ tube had an outward dilation near the midheight (Figures 13(c)-13(e)). In contrast, all hybrid DTCCs with a $\pm 45^{\circ}$ FRP tube exhibited severe damages with cracks following the fiber orientations (Figures 13(f)-13(h)). Severe outward buckling was observed for the inner steel tubes due to the much larger axial deformation for hybrid DTCCs with a $\pm 45^{\circ}$ FRP tube.

3.2. Key Test Results. As shown in Figure 14, the axial loadaxial strain curves of all hybrid DTCCs are shown in three groups. As mentioned above, axial strain gauges were installed on the outer FRP tube and the inner steel tube to monitor the deformation of the specimen. In addition, four LVDTs covering the full height were also employed. As discussed above, severe localized damages were observed for hybrid DTCCs. Therefore, the readings obtained from strain gauges may not reflect the strain state of the specimen when localized damages occurred. Consequently, the axial strain obtained from the four LVDTs, which reflects the average axial strain of the full height, is adopted.

The key test results of all specimens are summarized in Table 5. $N_{\max }$ is the peak axial load of hybrid DTCCs. $\varepsilon_{\mathrm{cu}}$ is the ultimate axial strain of the specimen when the FRP tube ruptured. $\varepsilon_{\mathrm{cu}} / \varepsilon_{\mathrm{co}}$ is the strain enhancement ratio of the 


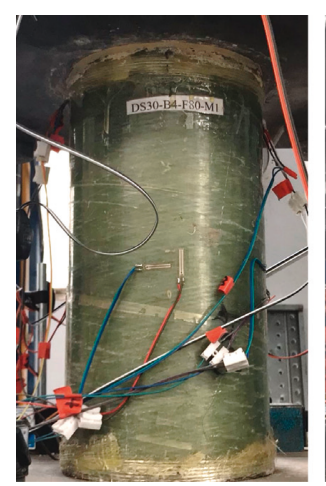

Timepoint A

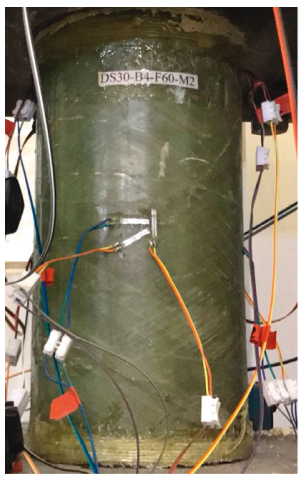

Timepoint A

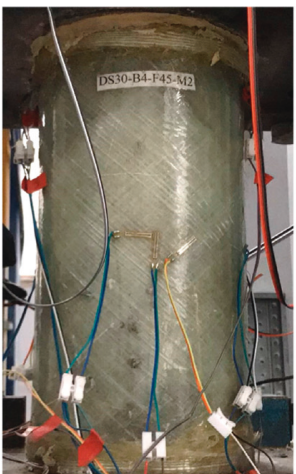

Timepoint A

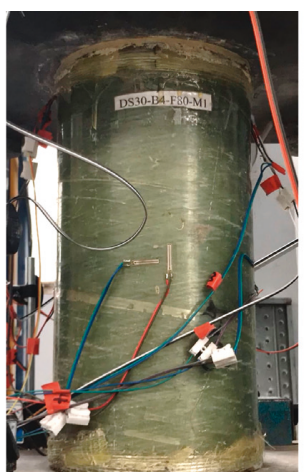

Timepoint B

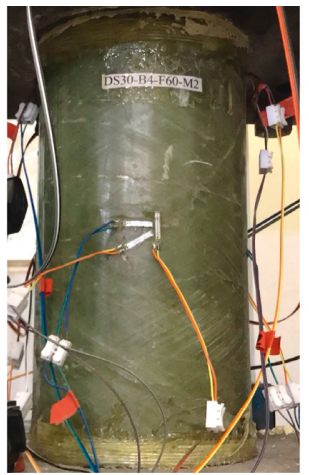

Timepoint B

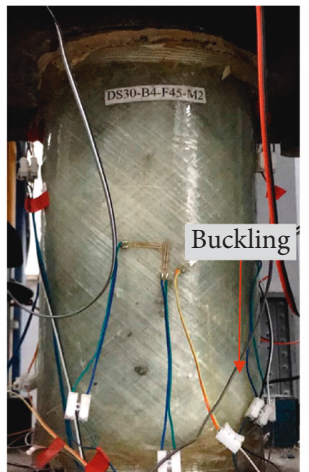

Timepoint B

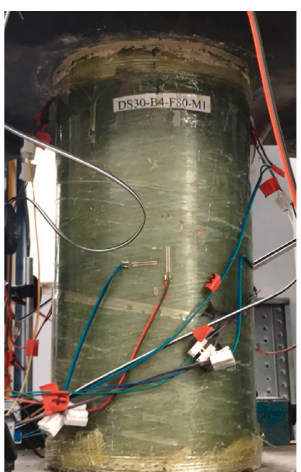

Timepoint C

(a)

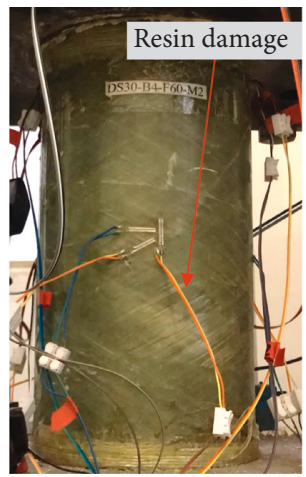

Timepoint C

(b)

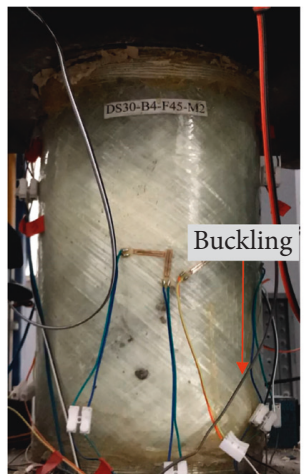

Timepoint C

(c)

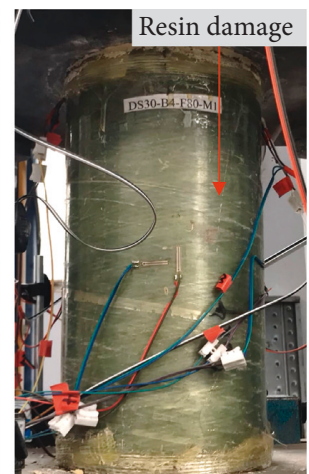

Timepoint D

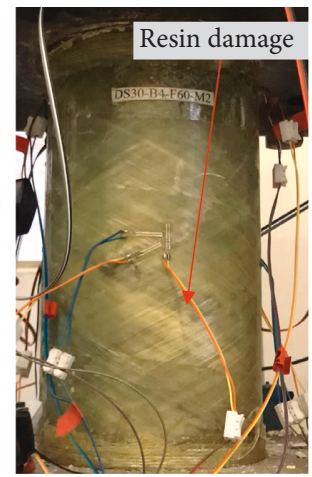

Timepoint D

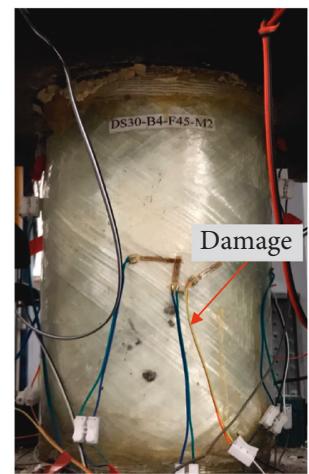

Timepoint D

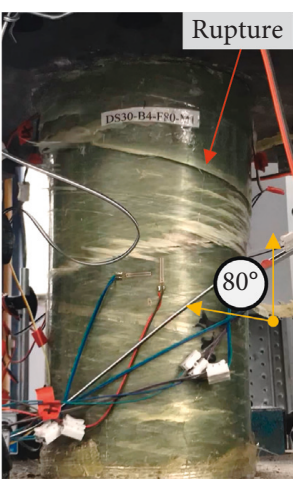

Timepoint E

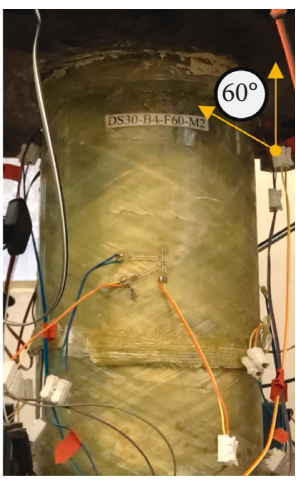

Timepoint E

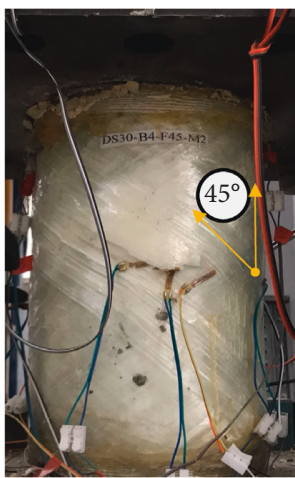

Timepoint E

Figure 11: Damage processes of typical specimens. (a) B4-F80-M1 $\left(\theta= \pm 80^{\circ} ; t_{\text {frp }}=4 \mathrm{~mm}\right.$; Type B steel tube). (b) B4-F60-M2 $\left(\theta= \pm 60^{\circ}\right.$; $t_{\text {frp }}=4 \mathrm{~mm}$; Type B steel tube). (c) B4-F45-M2 $\left(\theta= \pm 45^{\circ} ; t_{\text {frp }}=4 \mathrm{~mm}\right.$; Type B steel tube).

confined concrete. $\varepsilon_{\text {hrup }}$ is the average hoop rupture strain of the two identical hybrid DTCCs. Some of the hoop strain gauges, which failed to work before the rupture of the FRP tube, were excluded from the calculation of the average hoop rupture strain. For hybrid DTCCs with a $\pm 45^{\circ}$ FRP tube, strain gauges were all failed before the rupture of the FRP tube due to the extremely large axial deformation. Therefore, the averaged hoop rupture strain obtained from the splitdisk test of FRP rings with a width of $60 \mathrm{~mm}$ is listed in Table 5 for hybrid DTCCs with a $\pm 45^{\circ}$ FRP tube.
3.3. Effect of Fiber Angles. The effect of fiber angles on the axial load-strain curves of hybrid DTCCs is illustrated in Figure 14. The curves of each subfigure in Figure 14 are for a group of hybrid DTCCs with the same inner steel tube and the same FRP tube thickness but different fiber angles. For hybrid DTCCs with a $\pm 80^{\circ}$ FRP tube, the axial load-strain curves exhibit a first linear branch and then an ascending branch with a small nonlinearity. The axial load-strain curves of hybrid DTCCs with a $\pm 60^{\circ}$ FRP tube are similar to those of hybrid DTCCs with a $\pm 80^{\circ}$ FRP tube. Compared 


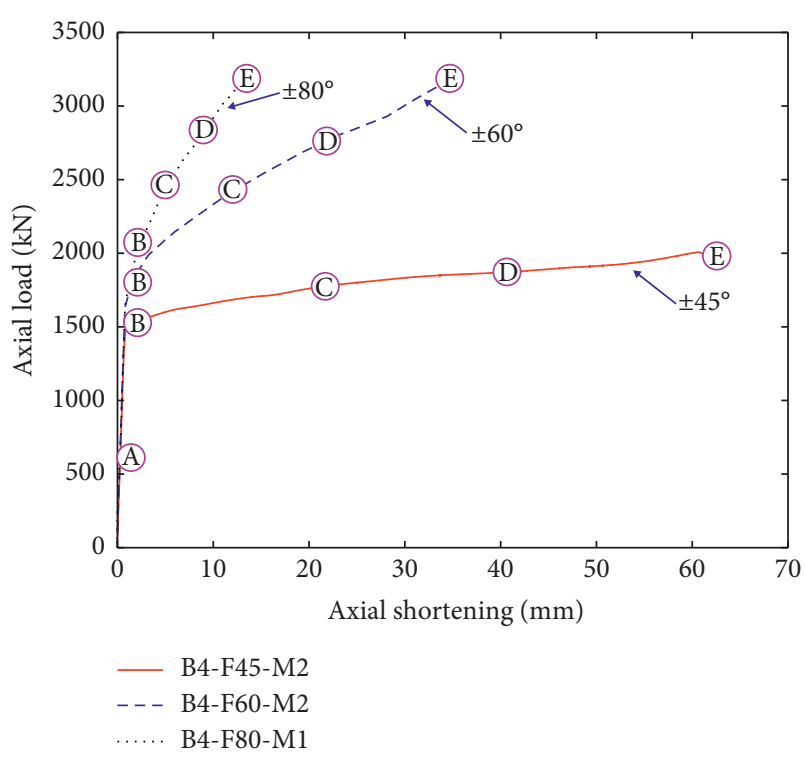

FIGURE 12: Axial load-axial shortening curves of typical specimens.

with hybrid DTCCs with a $\pm 80^{\circ}$ FRP tube, those specimens with a $\pm 60^{\circ} \mathrm{FRP}$ tube exhibited much better ductility without sacrificing the loading capacity (Figures 14(a) and 14(b)). In contrast, hybrid DTCCs with a $\pm 45^{\circ}$ FRP tube showed an approximately "elastic-perfectly plastic" shape for the axial load-axial strain curves, indicating their excellent ductility. Compared with hybrid DTCCs with a $\pm 60^{\circ}$ or $\pm 80^{\circ}$ FRP tube, the ductility of hybrid DTCCs with a $\pm 45^{\circ}$ FRP tube is much superior. It is evident that fiber angles have significant effects on the axial load-strain behaviors of hybrid DTCCs, especially for the stiffness of the second branch, the peak load, and the ultimate axial strain corresponding to the FRP rupture (Figure 14). As shown in Figure 6 and Table 2, the peak hoop stresses of $\pm 45^{\circ}, \pm 60^{\circ}$, and $\pm 80^{\circ}$ FRP tubes are 110.0 MPa, 415.7 MPa, and 557.5 MPa, respectively, whereas the ultimate hoop strains of $\pm 45^{\circ}, \pm 60^{\circ}$, and $\pm 80^{\circ}$ FRP tubes are $2.80 \%, 1.74 \%$, and $1.54 \%$, respectively. Therefore, given the same thickness and the same fiber-to-resin ratio, $\pm 45^{\circ} \mathrm{FRP}$ tubes provide smaller confinement but larger ductility enhancement for hybrid DTCCs, while $\pm 80^{\circ} \mathrm{FRP}$ tubes offer much stronger confinement but smaller ductility enhancement. As expected, the performance of $\pm 60^{\circ}$ FRP tubes is between that of $\pm 45^{\circ}$ and $\pm 80^{\circ}$ FRP tubes for hybrid DTCCs. As a result, the peak load of hybrid DTCCs increases with the increase of the absolute value of fiber angles, whereas the ultimate axial strain of hybrid DTCCs increases with the decrease of the absolute value of fiber angles.

3.4. Effect of FRP Tube Thickness. Two groups of hybrid DTCCs were prepared to investigate the effect of the thickness of the FRP tube (i.e., specimens A4-F45-M1,2 and A8-F45-M1,2; specimens A4-F60-M1,2 and A8-F60-M1,2). As shown in Figure 15, hybrid DTCCs with an FRP tube of $8 \mathrm{~mm}$ in thickness generally have larger peak loads and greater ultimate axial strains. The thickness of the FRP tube has a significant effect on the axial load-strain curves of hybrid DTCCs. When all the other parameters are the same, a specimen with a thicker FRP tube has a larger stiffness for the second branch of the axial load-strain curve, as well as greater strength enhancement and ductility improvement.

3.5. Composite Effect of Hybrid DTCCs. The composite effect of hybrid DTCCs is illustrated in Figure 16 using three typical specimens (i.e., A4-F45-M1, A4-F60-M1, and A4F80-M1). The axial load carried by the concrete is assumed to be the product of the concrete area in hybrid DTCCs and the axial stress of unconfined concrete at the same axial strain. When the axial strain exceeds the ultimate strain of unconfined concrete, the axial load of the concrete returns to zero. Similarly, the axial load carried by the FRP tube is assumed to be the same as the axial load obtained from hollow FRP tubes under axial compression (Figure 8). When the axial strain exceeds the ultimate strain of hollow FRP tubes, the axial load carried by the FRP tube in hybrid DTCCs returns to zero. For the steel tube, the axial load is assumed to be the same as the axial load of steel tubes found from the axial compression tests of hollow steel tubes in Figure 9. As shown in Figure 16, the sum of the axial loads of concrete, steel, and FRP is much lower than the actual load of hybrid DTCCs, indicating the significant composite effect of hybrid DTCCs, which is due to the effective confinement provided by the steel tube and the FRP tube. In hybrid DTCCs (Figure 1(c)), the concrete ring is mainly confined by the outer FRP tube, whereas the concrete core is under dual confinement provided by both the inner steel tube and the outer FRP tube, leading to strength enhancement and ductility improvement. By combining these three materials, hybrid DTCCs exhibit excellent performance in terms of load capacity and ductility.

\section{Comparison with Wang's Model}

4.1. Wang's Model. In hybrid DTCCs, the inner steel tube provides a direct contribution to the axial load and confines the concrete inside of the inner steel tube. Figure 17 shows the biaxial stress state of the inner steel tube for three typical hybrid DTCCs. The axial compressive stress is taken to be positive and the hoop tensile stress is taken to be negative in Figure 17. The stress increments in the steel tube for given strain increments were found using the average strains of the steel tube and the constitutive law of the inner steel tube as suggested by Teng et al. [30]. It is also recommended that the constitutive law of the steel tube is assumed to be an elastic-plastic material with strain hardening and governed by the J2 flow theory [30]. The direct axial load contribution of the inner steel tube is equal to the product of the axial tress in Figure 17 and the cross-sectional area of the steel tube. The hoop stress of the inner steel tube in Figure 17 is used to consider the confinement effect of the steel tube in the following predictions.

For FRP tubes, the direct contribution to the axial load of hybrid DTCCs should be considered properly. As discussed above, the local outward buckling occurred for the $\pm 45^{\circ}$ FRP tube at the early stage of the axial compression test of hybrid 


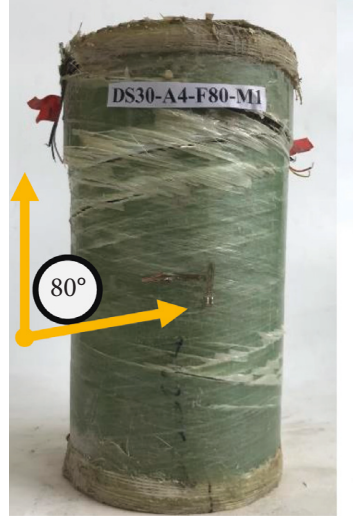

(a)
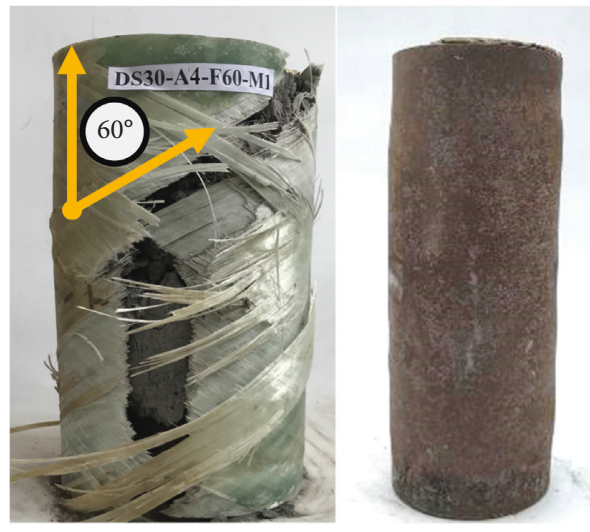

(c)

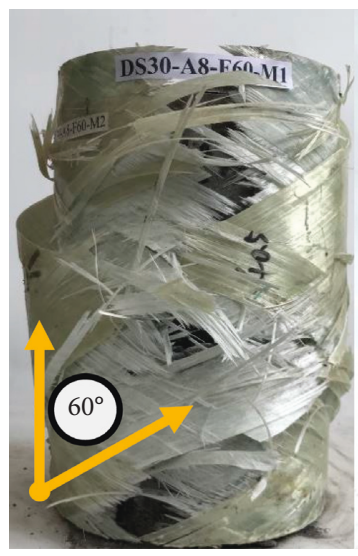

(e)
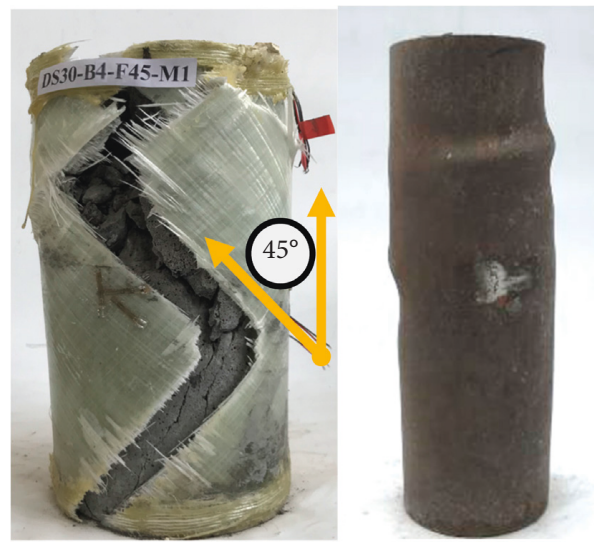

(g)

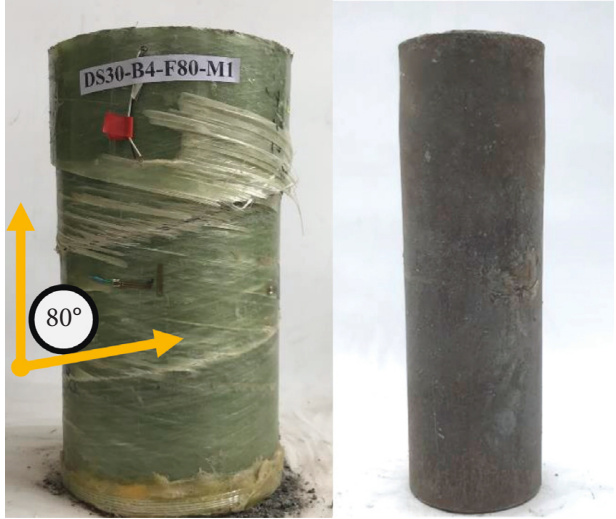

(b)

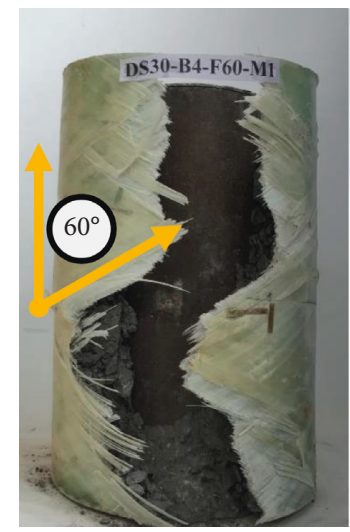

(d)

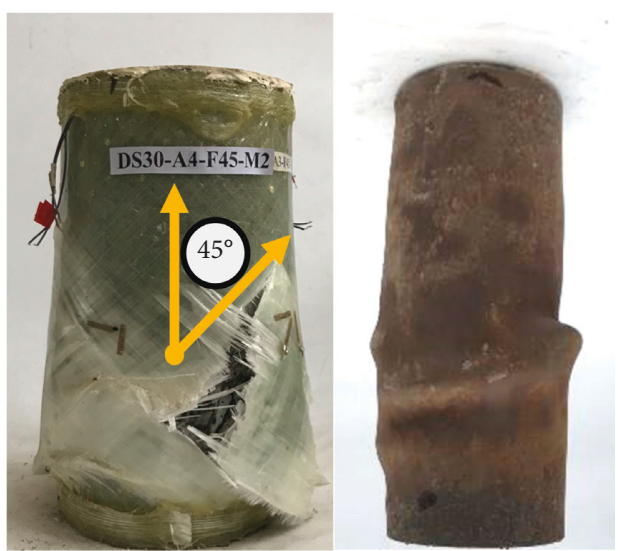

(f)

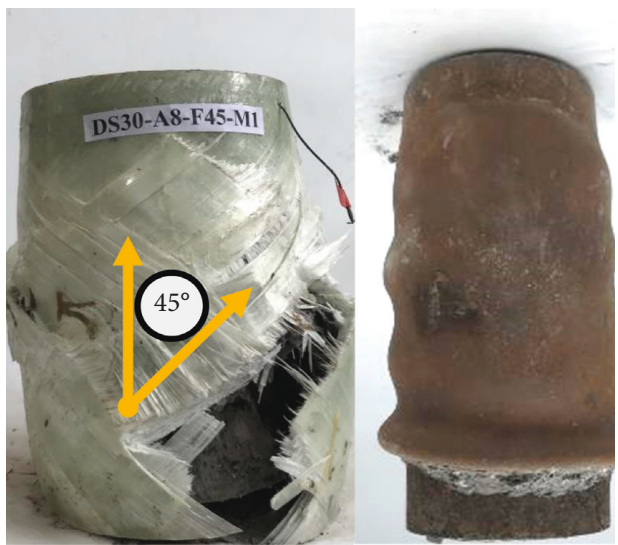

(h)

Figure 13: Typical DSTCs after test. (a) $\theta= \pm 80^{\circ} ; t_{\text {frp }}=4 \mathrm{~mm}$; Type A steel tube. (b) $\theta= \pm 80^{\circ} ; t_{\text {frp }}=4 \mathrm{~mm}$; Type B steel tube. (c) $\theta= \pm 60^{\circ}$; $t_{\text {frp }}=4 \mathrm{~mm}$; Type A steel tube. (d) $\theta= \pm 60^{\circ} ; t_{\text {frp }}=4 \mathrm{~mm}$; Type B steel tube. (e) $\theta= \pm 60^{\circ} ; t_{\text {frp }}=8 \mathrm{~mm}$; Type A steel tube. (f) $\theta= \pm 45^{\circ} ; t_{\text {frp }}=4 \mathrm{~mm}$; Type A steel tube. (g) $\theta= \pm 45^{\circ}$; $t_{\text {frp }}=4 \mathrm{~mm}$; Type B steel tube. (h) $\theta= \pm 45^{\circ} ; t_{\text {frp }}=8 \mathrm{~mm}$; Type A steel tube. 


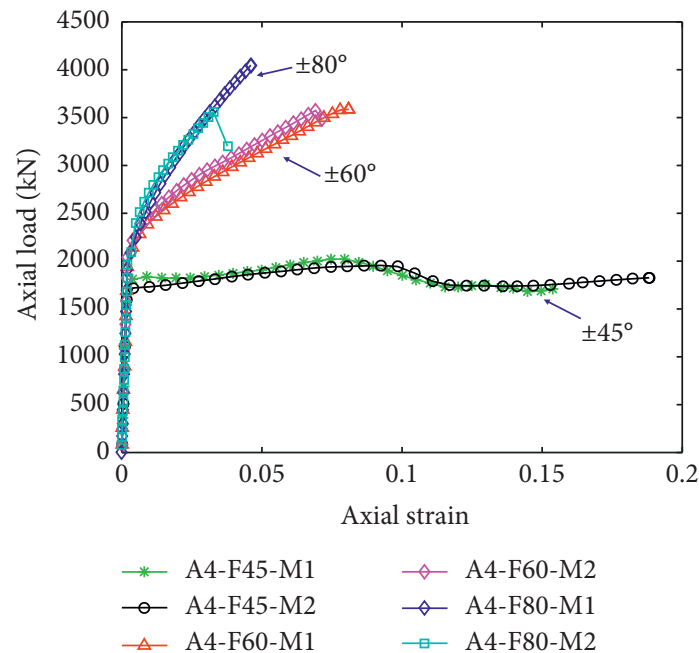

(a)

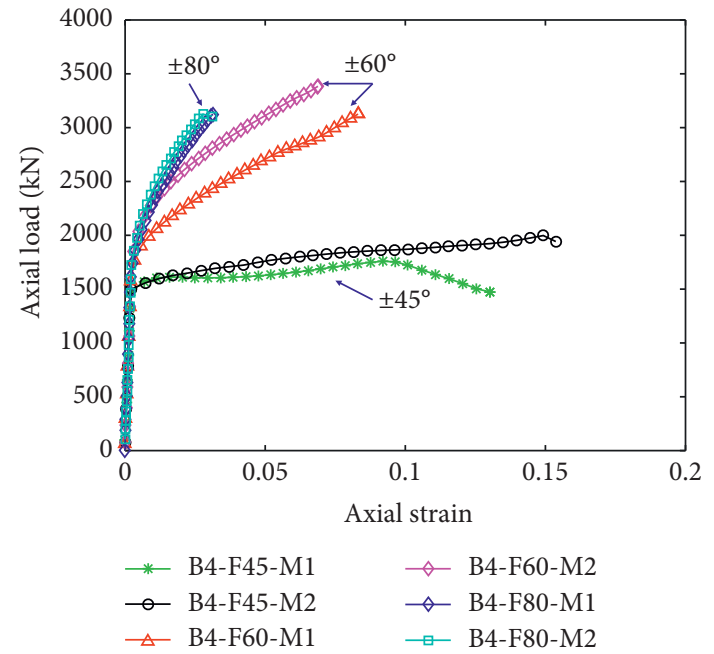

(b)

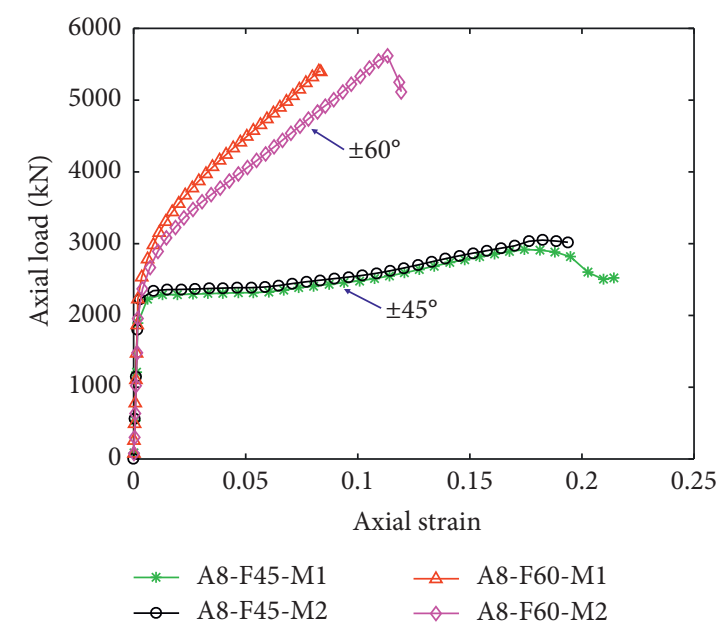

(c)

Figure 14: Effect of fiber orientations. (a) $t_{\text {frp }}=4 \mathrm{~mm}$; Type A steel tube. (b) $t_{\text {frp }}=4 \mathrm{~mm}$; Type B steel tube. (c) $t_{\text {frp }}=8 \mathrm{~mm}$; Type A steel tube.

TABLE 5: Key test results.

\begin{tabular}{lcccc}
\hline Specimen name & $N_{\max }(\mathrm{kN})$ & $\varepsilon_{\mathrm{cu}}(\%)$ & $\varepsilon_{\mathrm{cu}} / \varepsilon_{\mathrm{co}}$ & $\varepsilon_{\mathrm{hrup}}(\%)$ \\
\hline A4-F45-M1 & 2024.5 & 15.38 & 64.1 & \multirow{2}{*}{$3.03^{*}$} \\
A4-F45-M2 & 1956.0 & 18.82 & 78.4 & \\
\hline A4-F60-M1 & 3587.6 & 8.10 & 33.8 & \multirow{2}{*}{2.50} \\
A4-F60-M2 & 3577.4 & 7.14 & 29.7 & \\
\hline A4-F80-M1 & 3568.0 & 4.08 & 17.0 & \multirow{2}{*}{1.22} \\
A4-F80-M2 & 4046.5 & 4.61 & 19.2 & \\
\hline B4-F45-M1 & 1759.0 & 13.02 & 54.2 & \multirow{2}{*}{$3.03^{*}$} \\
B4-F45-M2 & 2007.2 & 15.37 & 64.0 & \\
\hline B4-F60-M1 & 3126.0 & 8.31 & 34.6 & \multirow{2}{*}{1.85} \\
B4-F60-M2 & 3384.0 & 6.88 & 28.7 & \\
\hline B4-F80-M1 & 3129.0 & 3.14 & 13.1 & \multirow{2}{*}{0.65} \\
B4-F80-M2 & 3128.8 & 3.11 & 12.9 & \\
\hline A8-F45-M1 & 2922.2 & 21.43 & 89.3 & \multirow{2}{*}{$3.03^{*}$} \\
A8-F45-M2 & 3051.9 & 19.37 & 80.7 & \\
\hline A8-F60-M1 & 5408.3 & 8.34 & 34.8 & \multirow{2}{*}{1.96} \\
A8-F60-M2 & 5618.1 & 11.94 & 49.7 & \\
\hline
\end{tabular}

*The averaged hoop rupture strain was obtained from the split-disk test of FRP rings with a width of $60 \mathrm{~mm}$.
DTCCs which had a significant negative effect on the axial bearing capacity of the FRP tube (Figures 11(c) and 12). Therefore, the direct contribution of the $\pm 45^{\circ}$ FRP tube to the axial load of hybrid DTCCs is neglected for the following predictions. For $\pm 80^{\circ}$ and $\pm 60^{\circ}$ FRP tubes, the axial load was found from the compression tests of hollow FRP tubes as mentioned above; when the axial strain exceeds the axial strain corresponding to the peak stress of the compression tests of hollow FRP tubes, it is assumed that the load resisted by the FRP tube is equal to its ultimate load as the inner concrete provides continuously lateral support to the FRP tube.

In hybrid DTCCs, the concrete ring (Figure $1(\mathrm{c})$ ) is mainly confined by the outer FRP tube, whereas the concrete core is under dual confinement provided by both the inner steel tube and the outer FRP tube. An analysis-oriented model was proposed by Wang [32] based on an analysisoriented model for circular FRP-confined solid concrete columns by Jiang and Teng [11]. For the concrete ring, Wang's model [32] consists of equations (1)-(7). In order to consider the dual confinement of the two tubes, Wang's 


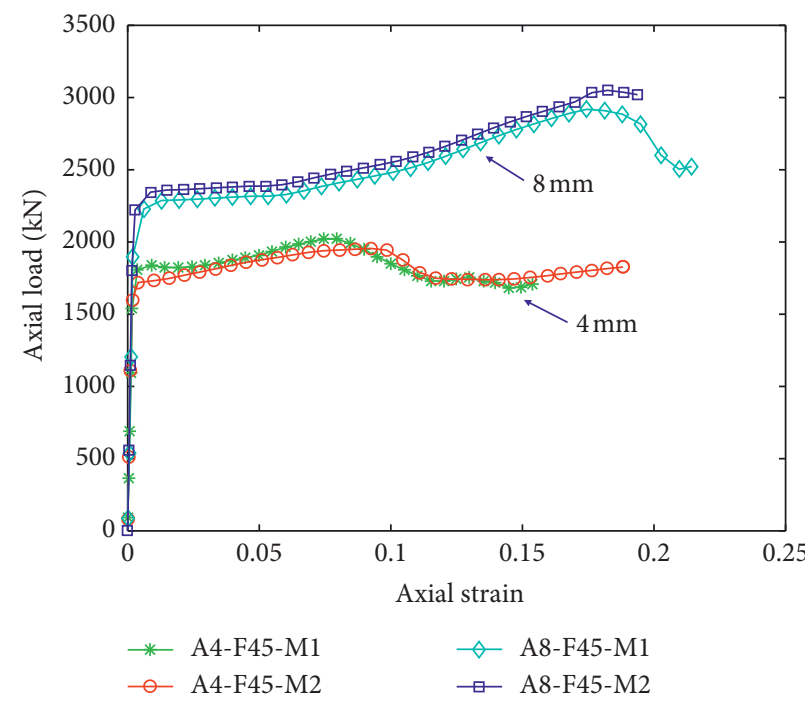

(a)

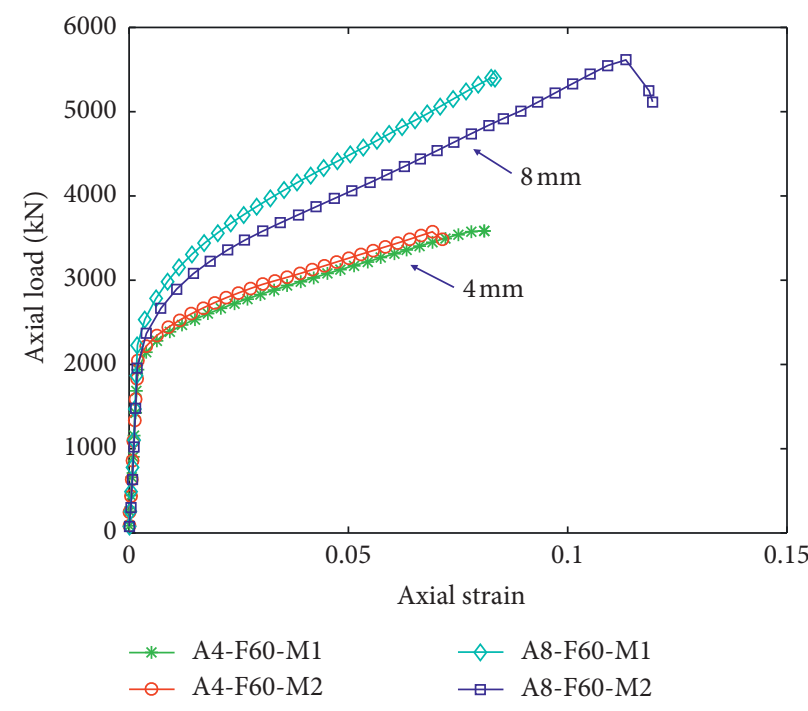

(b)

Figure 15: Effect of FRP tube thickness. (a) $\theta= \pm 45^{\circ}$; Type A steel tube. (b) $\theta= \pm 60^{\circ}$; Type A steel tube.

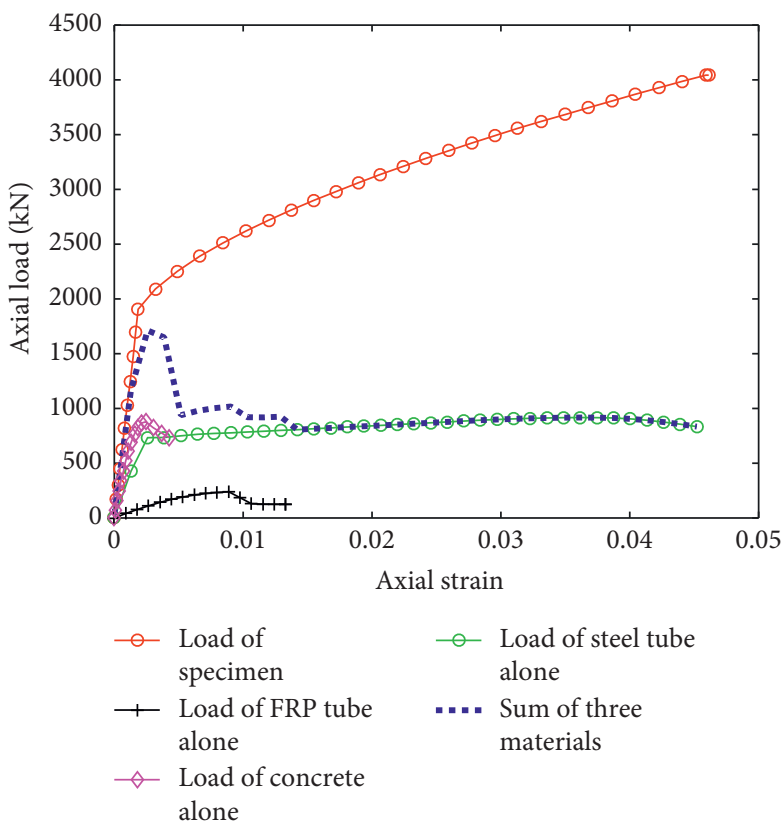

(a)

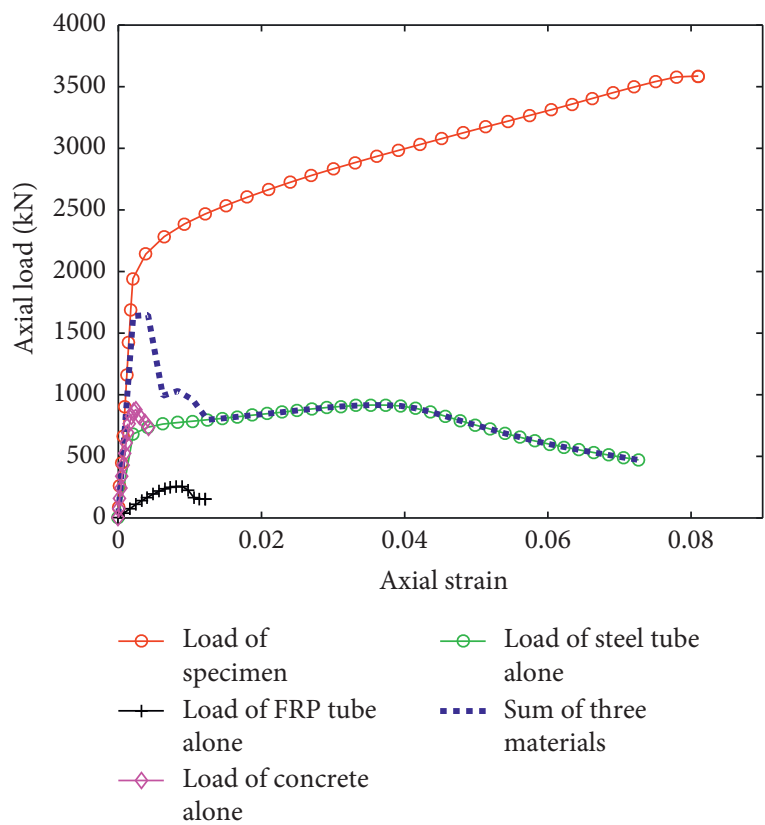

(b)

Figure 16: Continued. 


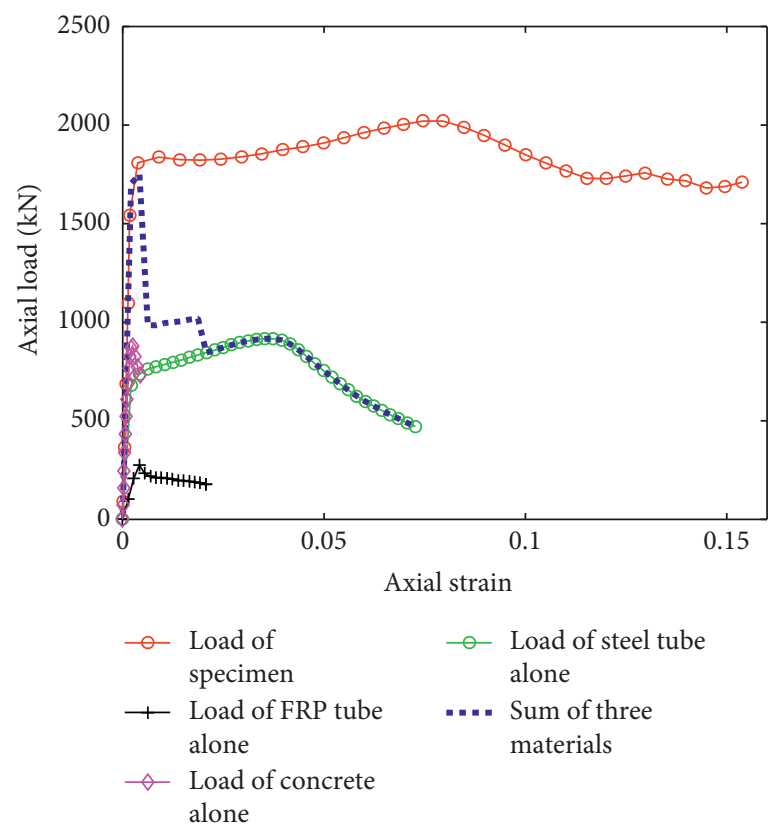

(c)

Figure 16: Composite effect of hybrid DTCCs. (a) A4-F80-M1 $\left(\theta= \pm 80^{\circ} ; t_{\text {frp }}=4 \mathrm{~mm}\right.$; Type A steel tube). (b) A4-F60-M1 $\left(\theta= \pm 60^{\circ}\right.$; $t_{\text {frp }}=4 \mathrm{~mm}$; Type A steel tube). (c) A4-F45-M1 $\left(\theta= \pm 45^{\circ} ; t_{\text {frp }}=4 \mathrm{~mm}\right.$; Type A steel tube).

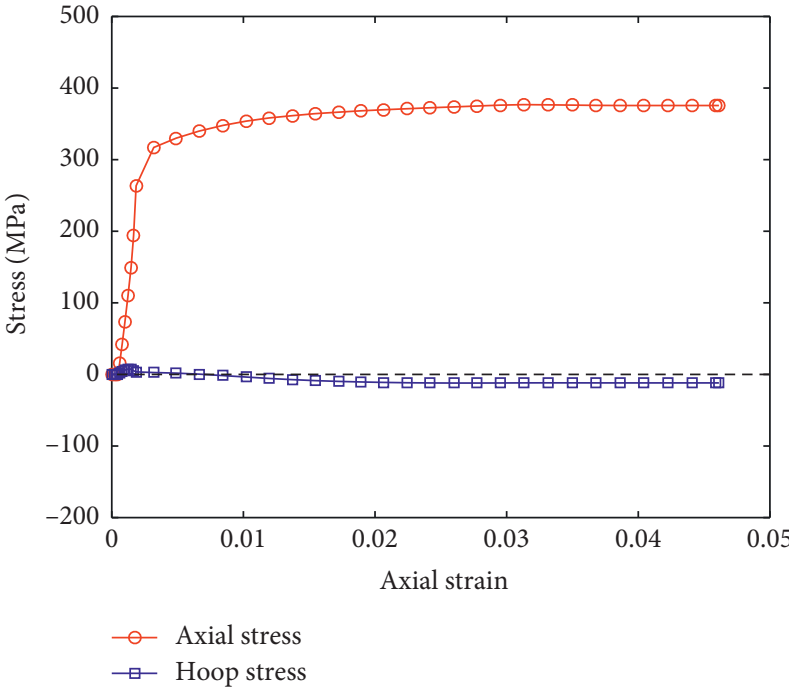

(a)

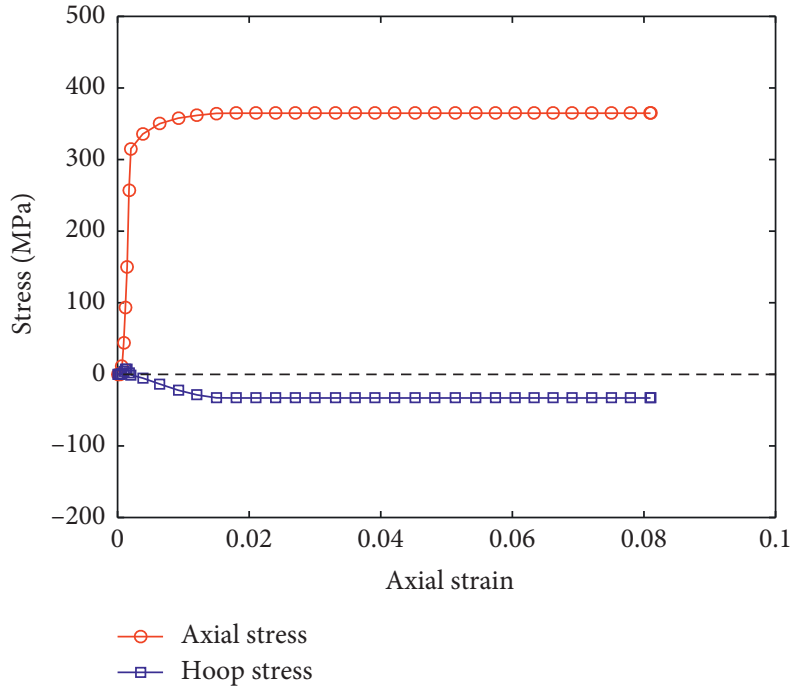

(b)

FIGURE 17: Continued. 


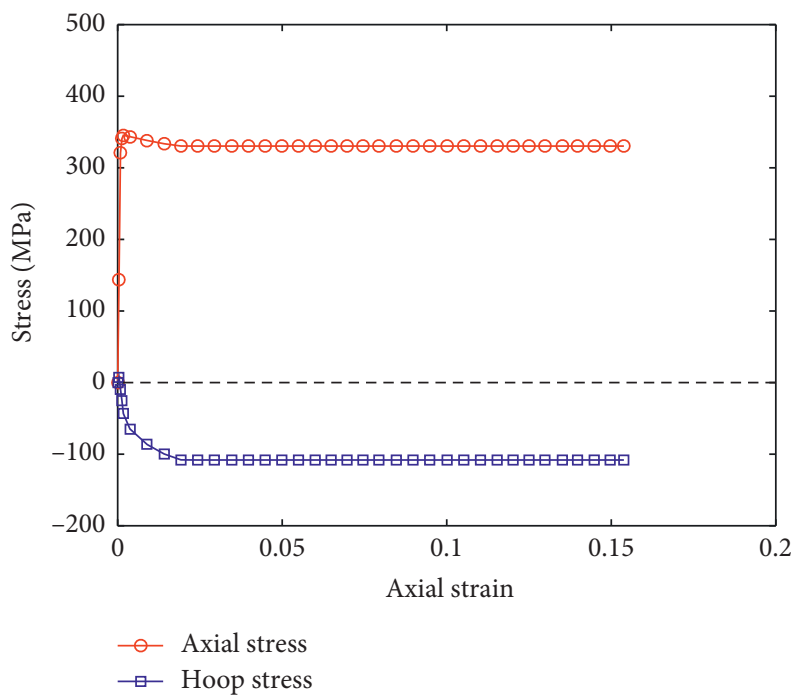

(c)

Figure 17: Stresses in the steel tubes of hybrid DTCCs. (a) A4-F80-M1 $\left(\theta= \pm 80^{\circ} ; t_{\text {frp }}=4 \mathrm{~mm}\right.$; Type A steel tube). (b) A4-F60-M1 ( $\theta= \pm 60^{\circ}$; $t_{\text {frp }}=4 \mathrm{~mm}$; Type A steel tube). (c) A4-F45-M1 $\left(\theta= \pm 45^{\circ} ; t_{\text {frp }}=4 \mathrm{~mm}\right.$; Type A steel tube).

model [32] consists of equations (1), (3), (4), (6), (7), and (8)-(10) for the concrete core. The incremental numerical procedures for generating the axial stress-strain curves of the concrete ring and the concrete core could be found in Ref. [32]. The incremental procedure should be terminated when the hoop strain $\varepsilon_{\mathrm{h}}$ exceeds the rupture strain of the FRP tube, $\varepsilon_{\mathrm{h} \text {,rup }}[11,32]$. Therefore, the axial load of the concrete ring and that of the concrete core could be found as the product of the axial stress of the confined concrete and their corresponding cross-sectional areas:

$$
\begin{aligned}
& \frac{f_{\mathrm{cc}}^{\prime *}}{f_{\mathrm{co}}^{\prime}}=1+3.5 \frac{\sigma_{1}}{f_{\mathrm{co}}^{\prime}}, \\
& \frac{\varepsilon_{\mathrm{cc}}^{\prime *}}{\varepsilon_{\mathrm{co}}}=1+1.75\left(\frac{\sigma_{l}}{f_{\mathrm{co}}^{\prime}}\right)^{1.2}, \\
& \sigma_{1}=-\frac{2 E_{\mathrm{frp}} t_{\mathrm{frp}} \varepsilon_{\mathrm{h}}}{D}, \\
& \varepsilon_{\mathrm{h}}=-\varepsilon_{\mathrm{l}}, \\
& \frac{\varepsilon_{\mathrm{c}}}{\varepsilon_{\mathrm{co}}}=0.85\left(1+8 \frac{\sigma_{1}}{f_{\mathrm{co}}^{\prime}}\right)\left\{\left[1+0.75\left(\frac{-\varepsilon_{1}}{\varepsilon_{\mathrm{co}}}\right)\right]^{0.7}\right. \\
& \left.-\exp \left[-7\left(\frac{-\varepsilon_{l}}{\varepsilon_{c o}}\right)\right]\right\} \text {, } \\
& \frac{\sigma_{\mathrm{c}}}{f_{\mathrm{cc}}^{\prime *}}=\frac{\left(\varepsilon_{\mathrm{c}} / \varepsilon_{\mathrm{cc}}^{\prime *} /\right) r}{r-1+\left(\varepsilon_{\mathrm{c}} / \varepsilon_{\mathrm{cc}}^{\prime *}\right)^{r}} \\
& r=\frac{E_{\mathrm{c}}}{E_{\mathrm{c}}-f_{\mathrm{cc}}^{\prime *} / \varepsilon_{\mathrm{cc}}^{\prime *}}
\end{aligned}
$$

$$
\begin{aligned}
\frac{\varepsilon_{\mathrm{cc}}^{\prime *}}{\varepsilon_{\mathrm{co}}}= & 1+5\left(\frac{f_{\mathrm{cc}}^{\prime *}}{f_{\mathrm{co}}^{\prime}}-1\right), \\
\sigma_{\text {lcore }}= & \frac{-2 E_{\mathrm{frp}} t_{\mathrm{frp}} \varepsilon_{\mathrm{h}} d_{\mathrm{s}} / D-2 \sigma_{\mathrm{sh}} t_{\mathrm{s}}}{d_{\mathrm{s}}-2 t_{\mathrm{s}}}, \\
\frac{\varepsilon_{\mathrm{c}}}{\varepsilon_{\mathrm{co}}}= & \left(-0.85 \frac{d_{\mathrm{s}}}{D}+2.14\right) \frac{f_{\mathrm{co}}^{\prime}}{30}\left(1+8 \frac{\sigma_{\text {lcore }}}{f_{\mathrm{co}}^{\prime}}\right) \\
& \cdot\left\{\left[1+0.75\left(\frac{-\varepsilon_{1}}{\varepsilon_{\mathrm{co}}}\right)\right]^{0.7}-\exp \left[-7\left(\frac{-\varepsilon_{1}}{\varepsilon_{\mathrm{co}}}\right)\right]\right\},
\end{aligned}
$$

where $f_{\mathrm{cc}}^{\prime *}$ and $\varepsilon_{\mathrm{cc}}^{\prime *}$ are the peak axial stress and the corresponding axial strain of confined concrete under a specific constant confining pressure (i.e., actively confined concrete), respectively; $f_{\text {co }}^{\prime}$ and $\varepsilon_{\text {co }}$ are the peak axial stress and the corresponding axial strain of unconfined concrete; $E_{\mathrm{c}}$ is Young's modulus of unconfined concrete; $E_{\text {frp }}$ is Young's modulus of the FRP tube in the hoop direction; $\varepsilon_{\mathrm{h} \text {,rup }}$ is the rupture strain of the FRP tube; $t_{\text {frp }}$ is the thickness of the FRP tube; $\sigma_{1}$ is the lateral confining pressure of the FRP tube; $D$ is the inner diameter of the FRP tube; $\varepsilon_{\mathrm{h}}$ is the hoop strain of the FRP tube; $\varepsilon_{\mathrm{c}}$ and $\varepsilon_{1}$ are the axial strain and the lateral strain of confined concrete, respectively; $d_{\mathrm{s}}$ and $t_{\mathrm{s}}$ are the outer diameter and the thickness of the inner steel tube; $\sigma_{\mathrm{sh}}$ is the hoop stress of the inner steel tube; and $\sigma_{\text {lcore }}$ is the confining pressure of the concrete inside of the inner steel tube.

4.2. Comparison. The axial load-axial strain curves of the present study are compared with Wang's [32] model in Figure 18. The predicted peak axial loads and the predicted ultimate axial strains of Wang's [32] model are compared with experimental results in Figure 19. It is evident that 


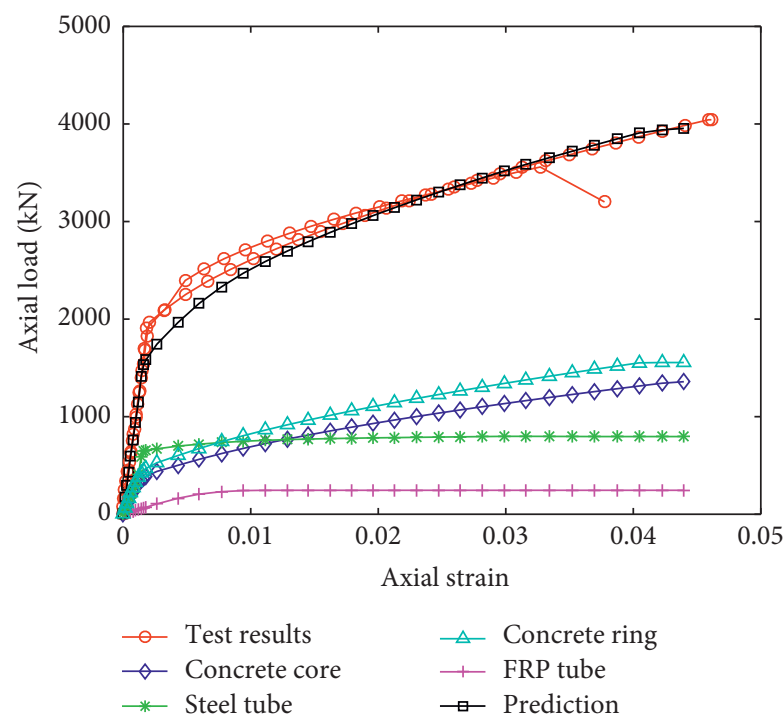

(a)

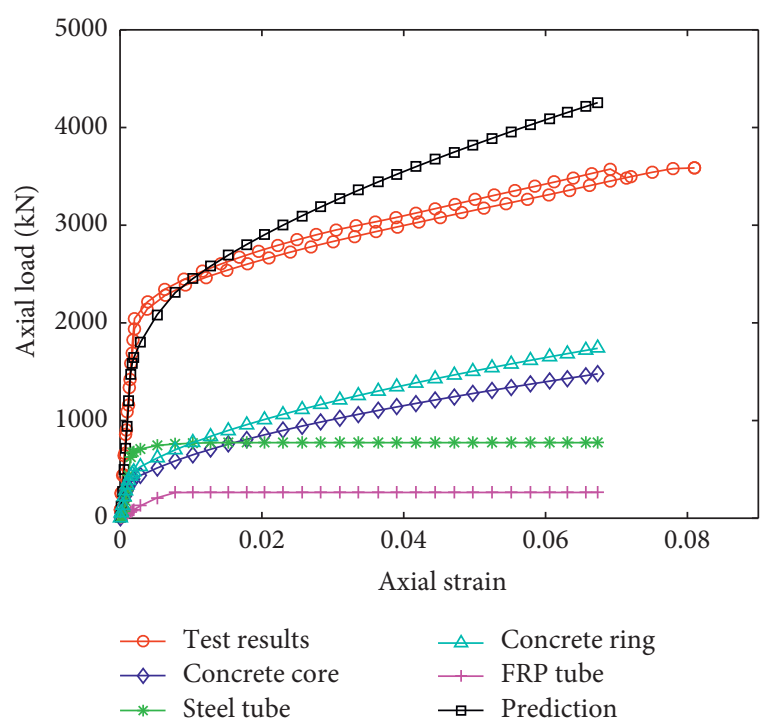

(c)

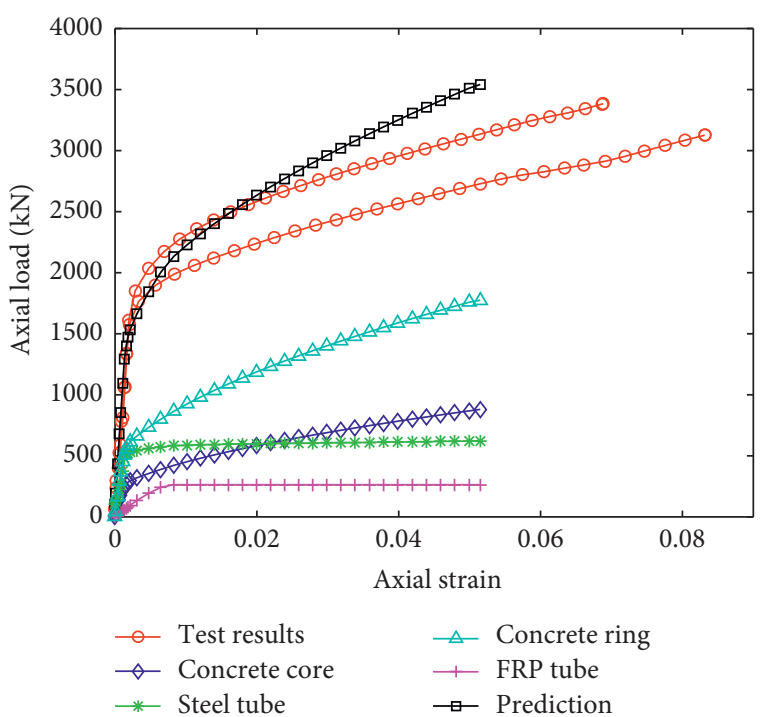

(e)

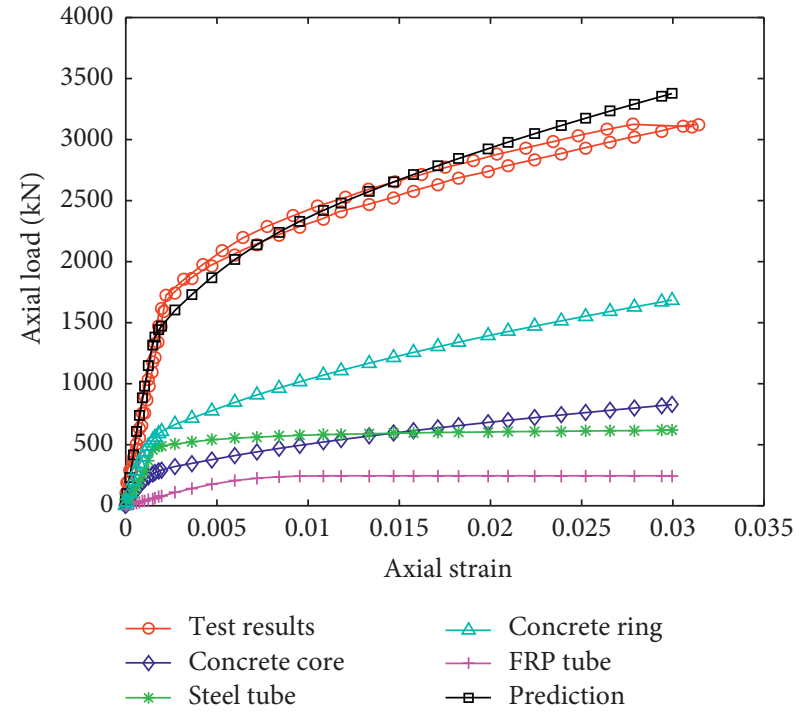

(b)

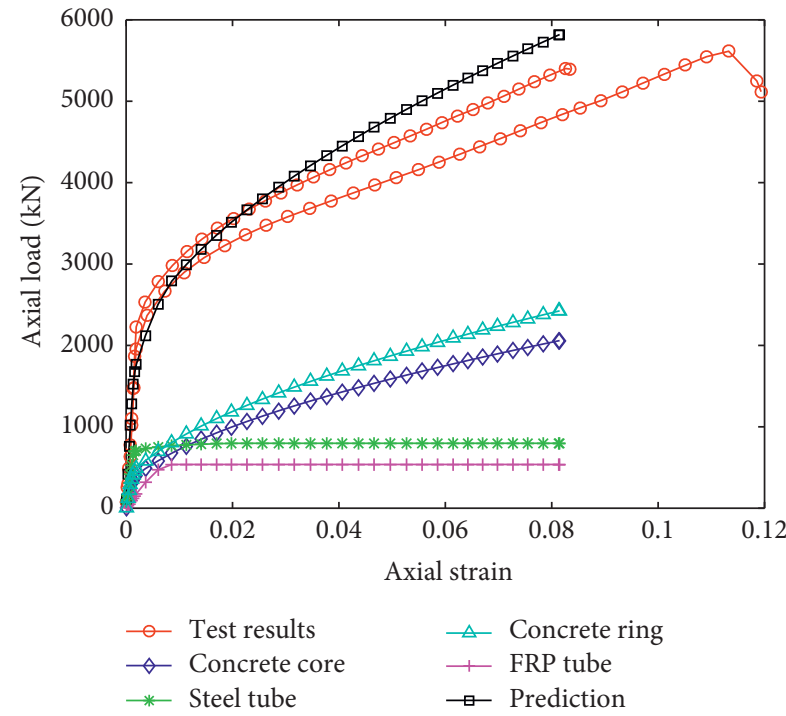

(d)

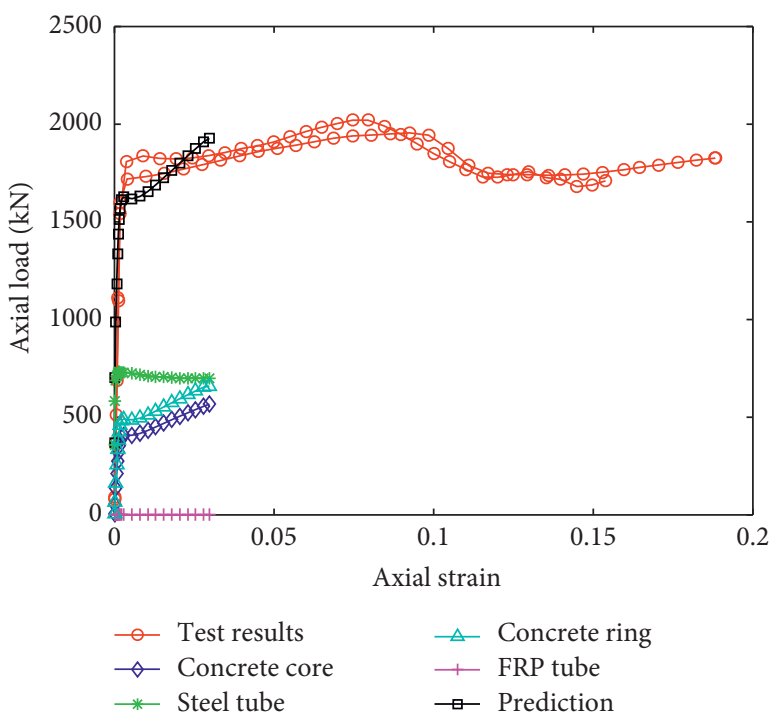

(f)

Figure 18: Continued. 


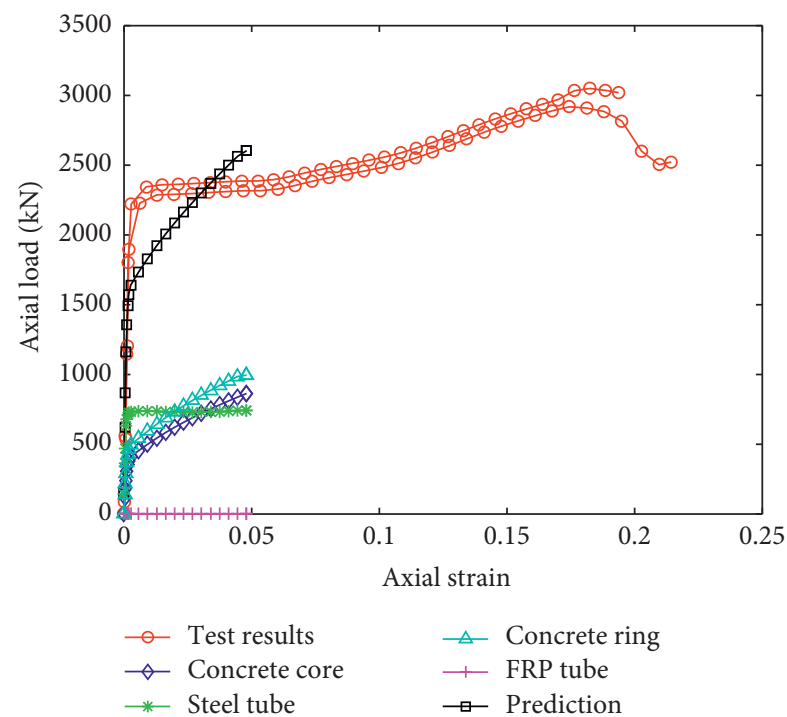

(g)

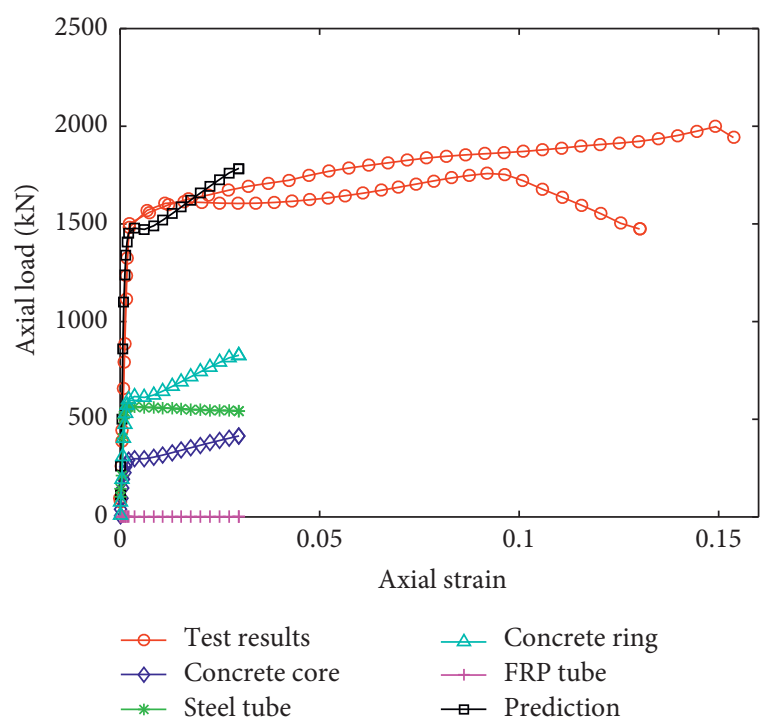

(h)

Figure 18: Comparisons of axial load-strain curves with Wang's [32] model. (a) A4-F80-M1,2. (b) B4-F80-M1,2. (c) A4-F60-M1,2. (d) A8F60-M1,2. (e) B4-F60-M1,2. (f) A4-F45-M1,2. (g) A8-F45-M1,2. (h) B4-F45-M1,2.

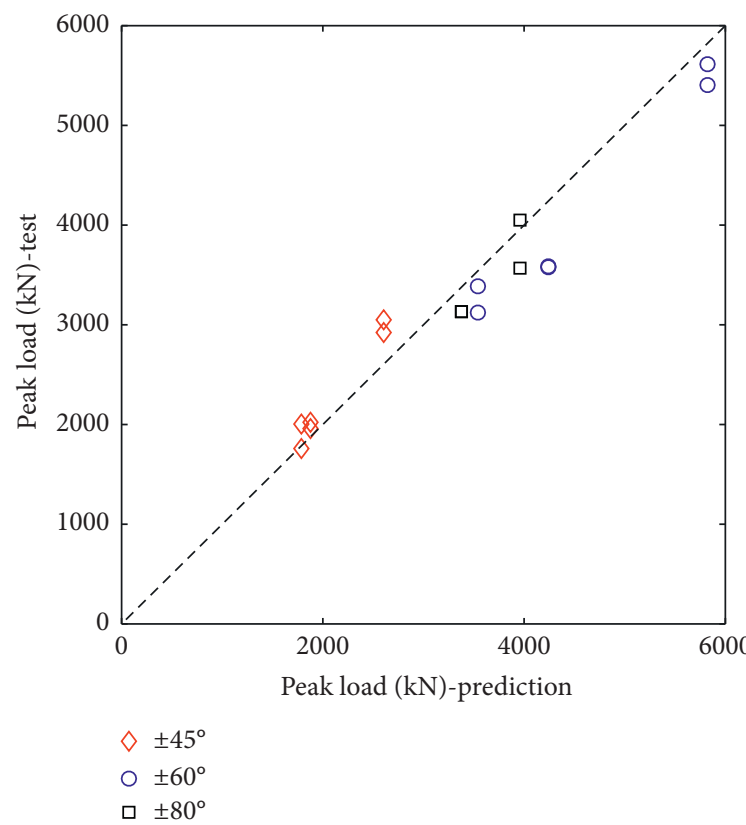

(a)

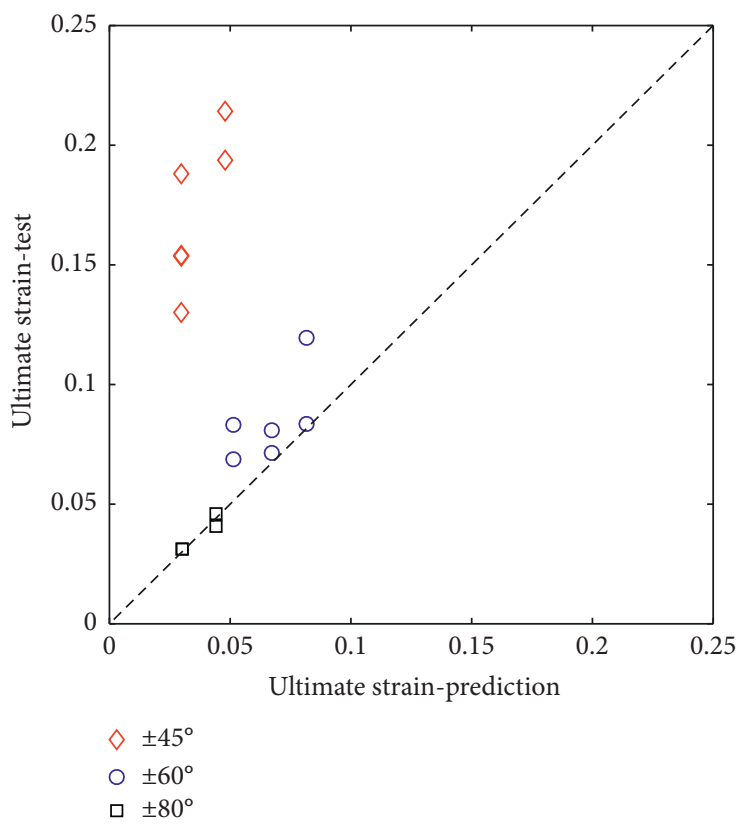

(b)

Figure 19: Predictions of Wang's [32] model. (a) Peak load. (b) Ultimate axial strain.

Wang's [32] model provides accurate predictions for peak axial loads for all hybrid DTCCs but consistently underestimates the ultimate axial strains for hybrid DTCCs with a $\pm 45^{\circ}$ or $\pm 60^{\circ}$ FRP tube. It is evident that Wang's [32] model provides accurate axial load-axial strain curves for hybrid DTCCs with a $\pm 80^{\circ}$ FRP tube (Figures 18 (a) and 18 (b)). However, for hybrid DTCCs with a $\pm 60^{\circ}$ FRP tube, the predicted stiffness of the second branch is larger than the experimental results (Figures 18(c)-18(e)). When obtaining the axial load contribution of FRP tubes, the biaxial stress state of FRP tubes was ignored. For $\pm 80^{\circ}$ FRP tubes, this measure is acceptable as their fibers in the FRP tubes are mainly oriented in the hoop direction. However, the hoop stiffness of $\pm 60^{\circ}$ FRP tubes under axial compression should be smaller than that obtained from split-disk tests due to the biaxial stress-state effect. Therefore, the hoop stiffness of 
$\pm 60^{\circ}$ FRP tubes obtained from split-disk tests, which is larger than the real hoop stiffness of $\pm 60^{\circ}$ FRP tubes in hybrid DTCCs under axial compression, is used for the prediction, leading to overestimated stiffness for the second branch of axial load-strain curves (Figures 18(c)-18(e)). For hybrid DTCCs with a $\pm 45^{\circ}$ FRP tube, the direct axial load contribution of the FRP tube is neglected as severe outward buckling occurred on the FRP tube during the compression test. As mentioned above, all hoop strain gauges on hybrid DTCCs with a $\pm 45^{\circ}$ FRP tube did not survive when the FRP tube ruptured. As shown in Figures 18(f)-18(h), Wang's [32] model predicts the axial load-axial strain curves for hybrid DTCCs with a $\pm 45^{\circ}$ FRP tube using the hoop rupture strain obtained from the split-disk test. Obviously, Wang's [32] model significantly underestimates the ultimate axial strain of hybrid DTCCs. As shown in Figures 5 and 6, the hoop rupture strain of $\pm 45^{\circ}$ FRP tubes is influenced significantly by the width of FRP rings. The hoop rupture strain obtained from the split-disk tests surely can reflect the real hoop rupture strain in hybrid DTTCs. As the damage process for hybrid DTTCs with a $\pm 45^{\circ}$ FRP tube was complicated by the local buckling of the FRP tube and the extremely large axial shortening, the ultimate axial strain could not be captured by Wang's [32] model. Nevertheless, Wang's [32] model successfully predicts the peak loads of hybrid DTCCs by considering the different confining states of the concrete ring and the concrete core in hybrid DTCCs (Figure 19).

\section{Conclusions}

This paper has presented an experimental study on hybrid DTCCs under monotonic axial compression with a particular focus on the effect of fiber angles of the FRP tube. The results and discussions presented in the paper allow the following conclusions to be drawn:

(1) Fiber angles have significant effects on the mechanical properties of FRP tubes and the axial loadstrain curves of hybrid DTCCs.

(2) The confinement effect of the FRP tube increases with the increase of the absolute value of fiber angles, whereas the ultimate axial strain of hybrid DTCCs decreases with the increase of the absolute value of fiber angles.

(3) The damage process of hybrid DTCCs with a $\pm 60^{\circ}$ FRP tube was similar to those with a $\pm 80^{\circ}$ FRP tube. However, for hybrid DTCCs with a $\pm 45^{\circ}$ FRP tube, severe outward buckling was observed near the bottom end of the specimen.

(4) Compared with hybrid DTCCs with a $\pm 80^{\circ} \mathrm{FRP}$ tube, those specimens with a $\pm 60^{\circ}$ FRP tube exhibited much better ductility without sacrificing the loading capacity. Hybrid DTCCs with a $\pm 45^{\circ}$ FRP tube showed an approximately "elastic-perfectly plastic" shape for the axial load-axial strain curves, indicating their excellent ductility.

(5) Wang's [32] model provides accurate predictions for hybrid DTCCs with a $\pm 80^{\circ}$ FRP tube. For hybrid
DTCCs with a $\pm 45^{\circ}$ or $\pm 60^{\circ}$ FRP tube, Wang's [32] model yields reasonable accurate predictions for the peak axial load but underestimates the ultimate axial strain consistently.

\section{Data Availability}

All tests were conducted by the authors. Requests for data, 12 months after publication of this article, will be considered by the corresponding author.

\section{Conflicts of Interest}

The authors declare that they have no conflicts of interest.

\section{Acknowledgments}

The authors are grateful for the financial support received from the National Key Research and Development Program of China (Grant no. 2017YFC0703405) and the National Natural Science Foundation of China (Grant nos. 51608263 and 51978332).

\section{References}

[1] J. G. Teng, "New-material hybrid structures," China Civil Engineering Journal, vol. 51, no. 12, pp. 1-11, 2008, in Chinese.

[2] L. C. Hollaway and J. G. Teng, Strengthening and Rehabilitation of Civil Infrastructures Using Fibrereinforced Polymer (FRP) Composites, Woodhead Publishing, Cambridge, UK, 2008.

[3] L. C. Bank, Composites for Construction: Structural Design with FRP Materials, John Wiley \& Sons, West Sussex, UK, 2006.

[4] Y. L. Wang, G. C. Cai, Y. Y. Li, D. Waldmann, A. S. Larbi, and K. D. Tsavdaridis, "Behavior of circular fiber-reinforced polymer-steel-confined concrete columns subjected to reversed cyclic loads: experimental studies and finite-element analysis," Journal of Structural Engineering, ASCE, vol. 145, no. 9, Article ID 4019085, 2019.

[5] B. Li, H. Xiong, J. Jiang, and X. Dou, "Tensile behavior of basalt textile grid reinforced Engineering Cementitious Composite," Composites Part B: Engineering, vol. 156, pp. 185-200, 2019.

[6] Y. Wei, G. Wu, and G. Li, "Performance of circular concretefilled fiber-reinforced polymer-steel composite tube columns under axial compression," Journal of Reinforced Plastics and Composites, vol. 33, no. 20, pp. 1911-1928, 2014.

[7] Z. Cai, D. Wang, S. T. Smith, and Z. Wang, "Experimental investigation on the seismic performance of GFRP-wrapped thin-walled steel tube confined RC columns," Engineering Structures, vol. 110, pp. 269-280, 2016.

[8] G. Lin, T. Yu, and J. G. Teng, "Design-oriented stress-strain model for concrete under combined FRP-steel confinement," Journal of Composites for Construction, vol. 20, no. 4, Article ID 4015084, 2015.

[9] Y. Xiao and H. Wu, "Compressive behavior of concrete confined by various types of FRP composite jackets," Journal of Reinforced Plastics and Composites, vol. 22, no. 13, pp. 1187-1201, 2003.

[10] G. Campione, L. Cavaleri, M. F. Ferrotto, G. Macaluso, and M. Papia, "Efficiency of stress-strain models of confined concrete with and without steel jacketing to reproduce 
experimental results," The Open Construction and Building Technology Journal, vol. 10, no. 1, pp. 65-86, 2016.

[11] T. Jiang and J. G. Teng, "Analysis-oriented stress-strain models for FRP-confined concrete," Engineering Structures, vol. 29, no. 11, pp. 2968-2986, 2007.

[12] M. F. Ferrotto, O. Fischer, and L. Cavaleri, "A strategy for the finite element modeling of FRP-confined concrete columns subjected to preload," Engineering Structures, vol. 173, pp. 1054-1067, 2018.

[13] Y. F. Wu and C. Jiang, "Effect of load eccentricity on the stress-strain relationship of FRP-confined concrete columns," Composite Structures, vol. 98, pp. 228-241, 2013.

[14] M. F. Ferrotto, O. Fischer, and L. Cavaleri, "Analysis-oriented stress-strain model of CRFP-confined circular concrete columns with applied preload," Materials and Structures, vol. 51, p. 44, 2018.

[15] Y. L. Bai, J. G. Dai, and J. G. Teng, "Cyclic compressive behavior of concrete confined with large rupture strain FRP composites," Journal of Composites for Construction, vol. 18, no. 1, Article ID 4013025, 2013.

[16] P. Castaldo, L. Cavaleri, and F. D. Trapani, "Stress-strain models for normal and high strength confined concrete: test and comparison of literature models reliability in reproducing experimental results," Ingegneria Sismica-International Journal of Earthquake Engineering, vol. 34, no. 3-4, pp. 114137, 2017.

[17] P. Li and Y. F. Wu, "Stress-strain model of FRP confined concrete under cyclic loading," Composite Structures, vol. 134, pp. 60-71, 2015.

[18] J. G. Teng, T. Yu, and Y. L. Wong, "Behaviour of hybrid FRPconcrete-teel double-skin tubular columns," in Proceedings, Second International Conference on FRP Composites in Civil Engineering, pp. 811-818, Adelaide, Australia, December 2004.

[19] J. G. Teng, T. Yu, Y. L. Wong, and S. L. Dong, "Hybrid FRPconcrete-steel tubular columns: concept and behavior," Construction and Building Materials, vol. 21, no. 4, pp. 846854, 2007.

[20] B. Zhang, J. G. Teng, and T. Yu, "Compressive behavior of double-skin tubular columns with high-strength concrete and a filament-wound FRP tube," Journal of Composites for Construction ASCE, vol. 21, no. 5, Article ID 4017029, 2017.

[21] T. Ozbakkaloglu, "A novel FRP-dual-grade concrete-steel composite column system," Thin-Walled Structures, vol. 96, pp. 295-306, 2015.

[22] B. A. L. Fanggi and T. Ozbakkaloglu, "Compressive behavior of aramid FRP-HSC-steel double-skin tubular columns," Construction and Building Materials, vol. 48, pp. 554-565, 2013.

[23] Y. Zhou, X. Liu, F. Xing, D. Li, Y. Wang, and L. Sui, "Behavior and modeling of FRP-concrete-steel double-skin tubular columns made of full lightweight aggregate concrete," Construction and Building Materials, vol. 139, pp. 52-63, 2017.

[24] L. Zeng, L. J. Li, Z. Su, and F. Liu, "Compressive test of GFRPrecycled aggregated concrete-steel tubular long columns," Construction and Building Materials, vol. 176, pp. 295-312, 2018.

[25] L. H. Han, Z. Tao, F. Y. Liao, and Y. Xu, "Tests on cyclic performance of FRP-concrete-steel double-skin tubular columns," Thin-Walled Structures, vol. 48, no. 6, pp. 430-439, 2010.

[26] B. Zhang, J. G. Teng, and T. Yu, "Experimental behavior of hybrid FRP-concrete-steel double-skin tubular columns under combined axial compression and cyclic lateral loading," Engineering Structures, vol. 99, pp. 214-231, 2015.

[27] J. L. Zhao, J. G. Teng, and T. Yu, "Behavior of large-scale hybrid FRP-concrete-steel double-skin tubular beams with shear connectors," Journal of Composite of ConstructionASCE, vol. 20, no. 5, Article ID 0, 2016.

[28] R. Wang, L. H. Han, and Z. Tao, "Behavior of FRP-concretesteel double skin tubular members under lateral impact: experimental study," Thin-Walled Structures, vol. 95, pp. 363-373, 2015.

[29] J. G. Teng and T. Yu, "Innovative combination of FRP, steel and concrete to achieve high-performance structures," in Proceedings, Second International Conference on Sustainable Urbanization, Hong Kong, China, January 2015.

[30] J. G. Teng, Z. Wang, T. Yu, Y. Zhao, and L. J. Li, "Double-tube concrete columns with a high-strength internal steel tube: concept and behaviour under axial compression," Advances in Structural Engineering, vol. 21, no. 10, pp. 1585-1594, 2018.

[31] J. J. Zeng, J. F. Lv, G. Lin, Y. C. Guo, and L. J. Li, "Compressive behavior of double-tube concrete columns with an outer square FRP tube and an inner circular high-strength steel tube," Construction and Building Materials, vol. 184, pp. 668-680, 2018.

[32] Z. H. Wang, Experimental and analytical study of double-tube concrete columns with an FRP external tube and a highstrength steel internal tube, Ph.D. thesis, Zhejiang University, 2017.

[33] ASTM D2290-08, Standard Test Method for Apparent Hoop Tensile Strength of Plastic or Reinforced Plastic Pipe by Split Disk Method, American Society for Testing and Materials (ASTM), Philadelphia, PA, USA, 2008.

[34] J. F. Chen, S. Q. Li, L. A. Bisby, and J. Ai, "FRP rupture strains in the split-disk test," Composites Part B: Engineering, vol. 42, no. 4, pp. 962-972, 2011.

[35] C. Kaynak, E. Salim Erdiller, L. Parnas, and F. Senel, "Use of split-disk tests for the process parameters of filament wound epoxy composite tubes," Polymer Testing, vol. 24, no. 5, pp. 648-655, 2005.

[36] GB/T5350-2005, Fiber-Reinforced Thermosetting Plastic Composites Pipe: Determination for Longitudinal Compressive Properties, The Standards Press of China, Beijing, China, 2005.

[37] ASTM C39/C39M, Standard Test Method for Compressive Strength of Cylindrical Concrete Specimens, American Society for Testing Materials, Philadelphia, PA, USA, 2008.

[38] BS 18, Tensile Testing of Metals (Including Aerospace Materials), British Standards Institution, London, UK, 1987. 


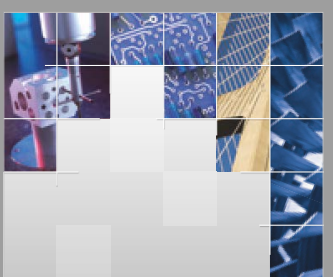

\section{Enfincering}
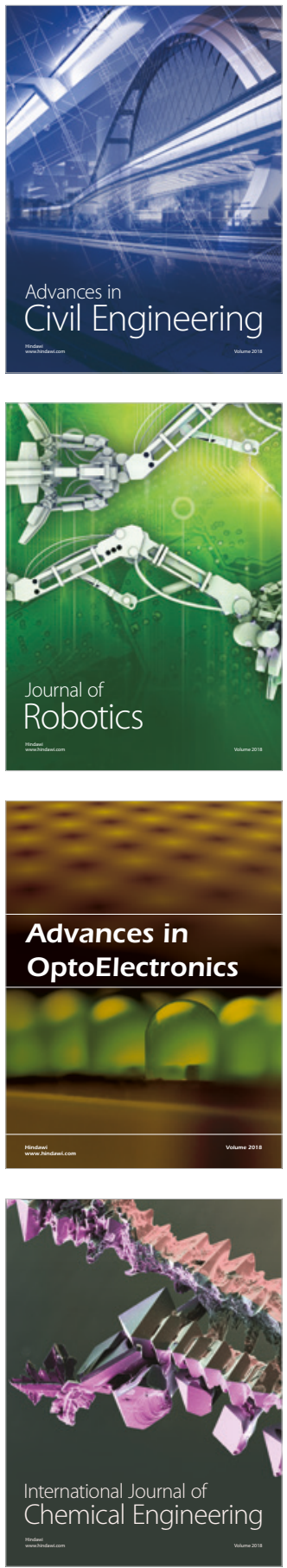

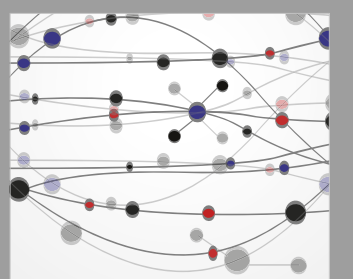

\section{Rotating \\ Machinery}

The Scientific World Journal

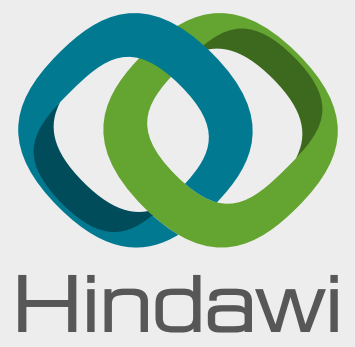

Submit your manuscripts at

www.hindawi.com
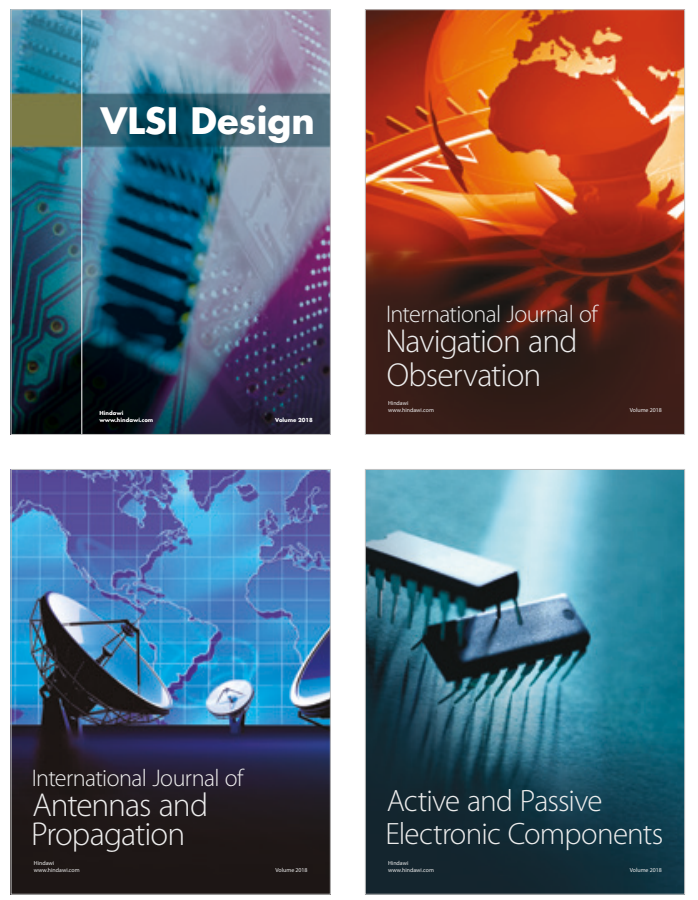
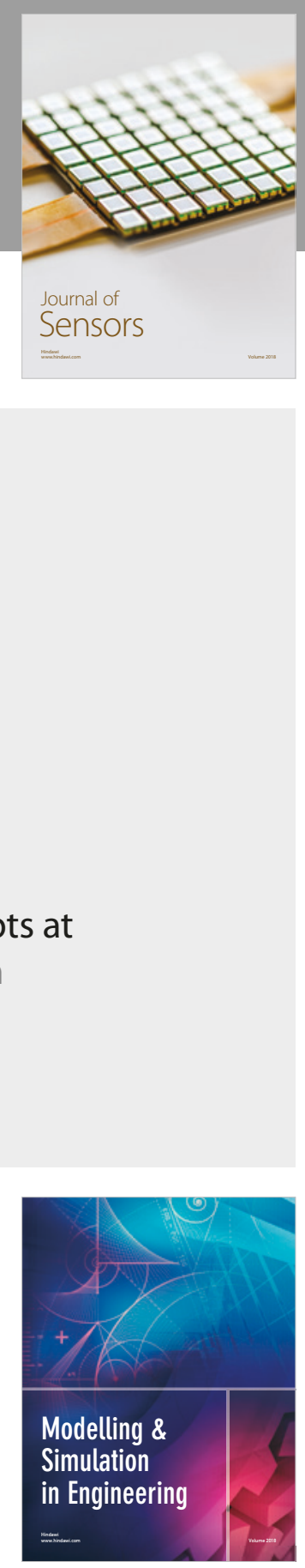

\section{Advances \\ Multimedia}
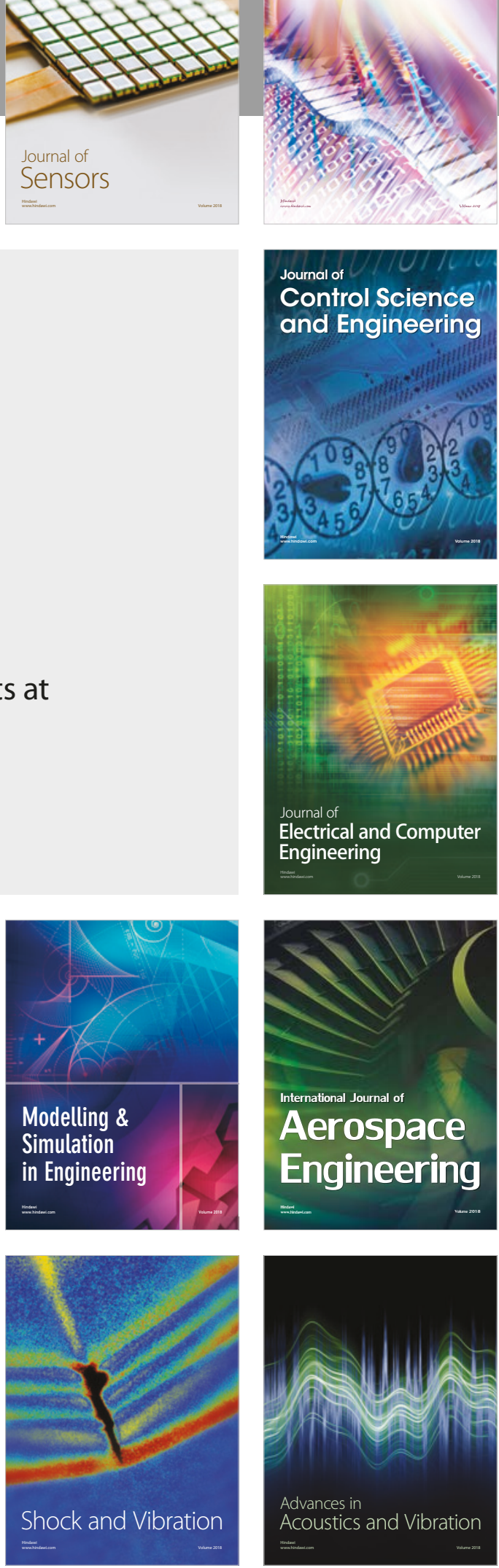